\title{
Fungal Cell Gigantism during Mammalian Infection
}

\author{
Oscar Zaragoza ${ }^{1,2 *}$, Rocío García-Rodas ${ }^{1}$, Joshua D. Nosanchuk ${ }^{2,3}$, Manuel Cuenca-Estrella ${ }^{1}$, Juan Luis \\ Rodríguez-Tudela ${ }^{1}$, Arturo Casadevall ${ }^{2,3}$
}

1 Servicio de Micología, Centro Nacional de Microbiología, Instituto de Salud Carlos III, Majadahonda, Madrid, Spain, 2 Department of Microbiology and Immunology, Albert Einstein College of Medicine, Bronx, New York, United States of America, 3 Department of Medicine, Albert Einstein College of Medicine, Bronx, New York, United States of America

\begin{abstract}
The interaction between fungal pathogens with the host frequently results in morphological changes, such as hyphae formation. The encapsulated pathogenic fungus Cryptococcus neoformans is not considered a dimorphic fungus, and is predominantly found in host tissues as round yeast cells. However, there is a specific morphological change associated with cryptococcal infection that involves an increase in capsule volume. We now report another morphological change whereby gigantic cells are formed in tissue. The paper reports the phenotypic characterization of giant cells isolated from infected mice and the cellular changes associated with giant cell formation. C. neoformans infection in mice resulted in the appearance of giant cells with cell bodies up to $30 \mu \mathrm{m}$ in diameter and capsules resistant to stripping with $\gamma$-radiation and organic solvents. The proportion of giant cells ranged from 10 to $80 \%$ of the total lung fungal burden, depending on infection time, individual mice, and correlated with the type of immune response. When placed on agar, giant cells budded to produce small daughter cells that traversed the capsule of the mother cell at the speed of $20-50 \mathrm{~m} / \mathrm{h}$. Giant cells with dimensions that approximated those in vivo were observed in vitro after prolonged culture in minimal media, and were the oldest in the culture, suggesting that giant cell formation is an aging-dependent phenomenon. Giant cells recovered from mice displayed polyploidy, suggesting a mechanism by which gigantism results from cell cycle progression without cell fission. Giant cell formation was dependent on CAMP, but not on Ras1. Real-time imaging showed that giant cells were engaged, but not engulfed by phagocytic cells. We describe a remarkable new strategy for $C$. neoformans to evade the immune response by enlarging cell size, and suggest that gigantism results from replication without fission, a phenomenon that may also occur with other fungal pathogens.
\end{abstract}

Citation: Zaragoza O, García-Rodas R, Nosanchuk JD, Cuenca-Estrella M, Rodríguez-Tudela JL, et al. (2010) Fungal Cell Gigantism during Mammalian Infection. PLoS Pathog 6(6): e1000945. doi:10.1371/journal.ppat.1000945

Editor: Aaron P. Mitchell, Carnegie Mellon University, United States of America

Received December 11, 2009; Accepted May 7, 2010; Published June 17, 2010

Copyright: (c) 2010 Zaragoza et al. This is an open-access article distributed under the terms of the Creative Commons Attribution License, which permits unrestricted use, distribution, and reproduction in any medium, provided the original author and source are credited.

Funding: O.Z. is supported by grants MPY1025/06, SAF2008-03761 and MPY1142/08 from Ministerio de Ciencia e Innovación and MPY1108/06 from Instituto de Salud Carlos III. A.C. is supported by grants NIH grants Al033774, HL059842, and 5R37AI033142. O.Z. held during part of this work a "Ramón y Cajal" contract. R.G.R. is supported by a FPI fellowship (reference BES-2009-015913). The funders had no role in study design, data collection and analysis, decision to publish, or preparation of the manuscript.

Competing Interests: The authors have declared that no competing interests exist.

* E-mail: ozaragoza@isciii.es

\section{Introduction}

The interaction between a microbe and a host involves a complex response by both the pathogen and the infected individual. The host has multiple defence mechanisms to avoid infection, damage and disease. Microbial pathogens adapt to survive in a host through multiple changes that include signalling pathways that confer the capacity to survive immune-mediated stresses. Both entities, the host and the microbe, interact and each contributes to the outcome of infection [1].

In the case of fungal pathogens, the interaction with the host frequently results in morphological changes. For example, Candida albicans forms pseudohyphae and true hyphae during infection, phenomena associated with virulence $[2,3,4]$. Other examples of fungal pathogens that form filaments during infection are Aspergillus species and the agents of zygomycosis. In contrast, Histoplasma capsulatum and Blastomyces dermatitidis manifest a temperature regulated dimorphism, such that at ambient temperatures they form filaments and at $37^{\circ} \mathrm{C}$ transform into yeast cells $[5,6,7]$. Although the role of these morphological transitions is not completely understood, it is believed that the phenomenon of fungal dimorphism plays an important function during the interaction of each of these microbes with their host.

The fungus Cryptococcus neoformans is the causative agent of cryptococcosis, a disease responsible for over 600,000 deaths per year, which makes this pathogen a major global threat. Cryptococcosis is currently the fourth leading cause of death from infectious diseases in Sub-Saharan Africa [8]. C. neoformans is unique among the major fungal pathogens in that it possesses a polysaccharide capsule surrounding a yeast cell body [9]. Capsular polysaccharides are also released into host tissues [10,11,12], where they mediate numerous deleterious effects on host immune function $[13,14,15]$. In fact, the polysaccharide capsule is the factor that makes the greatest contribution to the virulence of $C$. neoformans [16].

Although C. neoformans can form pseudohyphae during mating [9], this pathogen is mainly found in host tissues as round yeast cells. However, there is a specific morphological change associated with cryptococcal infection that involves a significant increase in capsule volume. Capsule size in C. neoformans depends on the growth condition (reviewed in [17]). While capsule size is relatively small in standard laboratory media and in the environment, it 


\section{Author Summary}

In this article we describe the formation of giant cells by the human fungal pathogen Cryptococcus neoformans during infection, involving an approximately 900-fold increase in volume compared to that of yeast cells grown in vitro. This switch to gigantism is a dramatic transition that is posited to have important consequences during infection. The paper reports the phenotypic characterization of these cells and the relationship between giant cell formation and polyploidy which suggests that gigantism is achieved by continued cell growth and DNA replication without fission. During infection, we observed an inverse correlation between the proportion of giant cells in the lung of infected mice and the inflammatory response elicited by the animals. In conclusion, our results indicate that during infection, C. neoformans forms giant cells, which might be implicated in fungal survival in the host during long time periods, especially during chronic and asymptomatic infection. The capacity for gigantism is an important new facet in fungal pathogenesis that provides the pathogen with the ability to escape host defences. We propose that the transition to gigantism can have profound consequences for the host-pathogen interaction including promoting fungal persistence in the host that can translate into latency and disease relapses.

undergoes a large increase in capsule size during pulmonary infection [18], such that it can comprise more than $90 \%$ of the total volume of the cell [19]. Capsular enlargement is believed to confer an advantage to the microorganism during its interaction with the host. For example, capsule growth interferes with complement-mediated phagocytosis [20] and protects the yeast cell against free radicals and antimicrobial agents [21]. Furthermore, increased capsule size makes the yeast more difficult to phagocytose by a variety of phagocytic cells, including amoebas that can prey upon C. neoformans in the environment [21].

We now report another morphological change whereby gigantic fungal cells are formed in tissue. This change is achieved, not only by a significant increase in capsule size, but also by an enlargement of the cell body. During pulmonary infection, we observed that a significant proportion of yeasts in the lung had cell volumes 900fold larger than cells grown in standard laboratory conditions. In retrospect, giant cells have been noted in prior studies $[18,22,23,24,25]$, but were never isolated or studied. The emergence of fungal giant cells poses a formidable problem for the immune system. In this study we present experimental evidence suggesting that $C$. neoformans gigantism may be a strategy that confers upon the organism the ability to survive within the host for long time periods.

\section{Results}

\section{C. neoformans produce gigantic cells during infection}

While the typical size of $C$. neoformans cells ranges between 4-8 microns (Figure 1A), we confirm the existence and report the recovery of $C$. neoformans cells of enormous size formed during infection (Figure 1B). Although these cells manifested a large increase in capsule size, there was also a concomitant increase in cell body size. The cell body reached $25-30 \mu \mathrm{m}$ in diameter, which was almost 7 -fold greater than the $4.5 \mu \mathrm{m}$ average size observed in vitro. This effect was more dramatic if the size of the capsule was included, with the giant cell size typically ranging from 40 to $60 \mu \mathrm{m}$ in diameter, although extremely large cells with diameters around $70-100 \mu \mathrm{m}$ were occasionally observed. If one considers volume applying the formula for a sphere $(\mathrm{V}=$ $\left.4 / 3 \times \pi \times\left(\mathrm{r}^{3}\right)\right)$, then giant cell formation involved an increase of 900 -fold in cellular volume, compared to cells grown in Sabouraud medium. We investigated whether the phenomenon was found in different cryptococcal strains. Consequently, we infected different individual mice with ten different $C$. neoformans strains (both serotype A and D, including standard strains, such as H99, 24067 or B3501, and clinical isolates from the Yeast Collection of the Spanish Mycology Reference Laboratory). For all strains, we found giant cells after three weeks of infection, indicating that this phenomenon applied to diverse strains (results not shown). Hence, we focused our efforts on the model serotype A strain H99, and we arbitrarily defined giant cells as those with a cell diameter greater than $30 \mu \mathrm{m}$ (capsule included), a size that is 5-6 times the usual size observed in vitro, and is virtually never encountered during in vitro experimental conditions. Using this strain, we observed giant cell formation in four different mouse strains (CD1, BALB/c, $\mathrm{C} 57 \mathrm{BL} / 6 \mathrm{~J}$ and $\mathrm{CBA} / \mathrm{J}$ ), indicating that the emergence of giant cells was also not mouse strain specific.

\section{Morphological features of the giant cells}

Giant cells had different cellular features than cells of regular size (Figure 1). Giant cells frequently contained multiple vesicles of unknown function that could reach more than 50 per cell (Figure 1C). In addition, there was usually a single enlarged vesicle that occupied a significant proportion of the cell body volume. To better identify these intracellular structures, we stained the cells with the vacuole specific marker MDY-64. In regular cells, we normally observed the presence of a single vacuole (Figure 1D). In giant cells, we observed two patterns of staining with this specific marker (Figure 1E,F). Multiple vesicles which stained with the vacuole marker were identified in approximately $50 \%$ of giant cells, whereas the remainder displayed staining mainly in a single large intracellular vesicle. These results suggest that in some giant cells, the vacuole fragmented into multiple vesicles or the smaller vesicles failed to coalesce.

A peculiarity of the giant cells was the abnormally large width of their cell wall. This feature was most apparent when the cells were observed by transmission electron microscopy. Using this technique, we could determine that the cell wall of regular cells had a width between 50-100 nm (Figure 1G). In contrast, the width in giant cells was 20-30 larger, ranging from 2 to $3 \mu \mathrm{m}$ (Figure 1H,I). In these pictures, it was also apparent that the density of the capsule differed between regular and giant cells. In the case of yeast obtained in vitro, the cells displayed a low density capsule with individual polysaccharide fibers attached to the cell wall (Figure 1G). In giant cells, the capsule was significantly denser in the regions close to the cell wall (Figure 1H,I).

Fungal cell suspensions recovered from the lungs of infected mice had a dark brownish colour. We hypothesized that this phenomenon could be due to in vivo pigment accumulation at the cell wall level, in particular melanin [26]. To investigate this hypothesis, we stained giant cells with specific mAbs to melanin [27]. Giant C. neoformans cells bound mAb to melanin at the cell wall level (Figure 1J,K), suggesting that this structure was melanized. In addition, we observed that giant cells showed a high degree of autofluorescence (result not shown), which has been reported in cryptococcal cells grown in certain media [28].

Scanning electron microscopy images suggested that the capsule of giant cells was different from that of cells grown in vitro. For cells grown in standard Sabouraud medium we noted that the dehydration and fixing process resulted in polysaccharide shrinkage and aggregation of fibers such that regions of the cell wall became exposed (Figure 2A). In contrast, the architecture of 

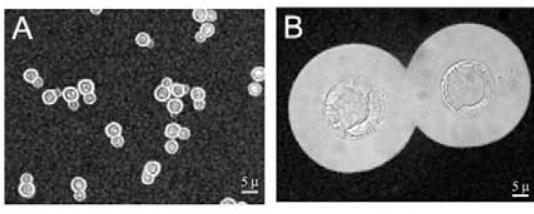

Light microscopy
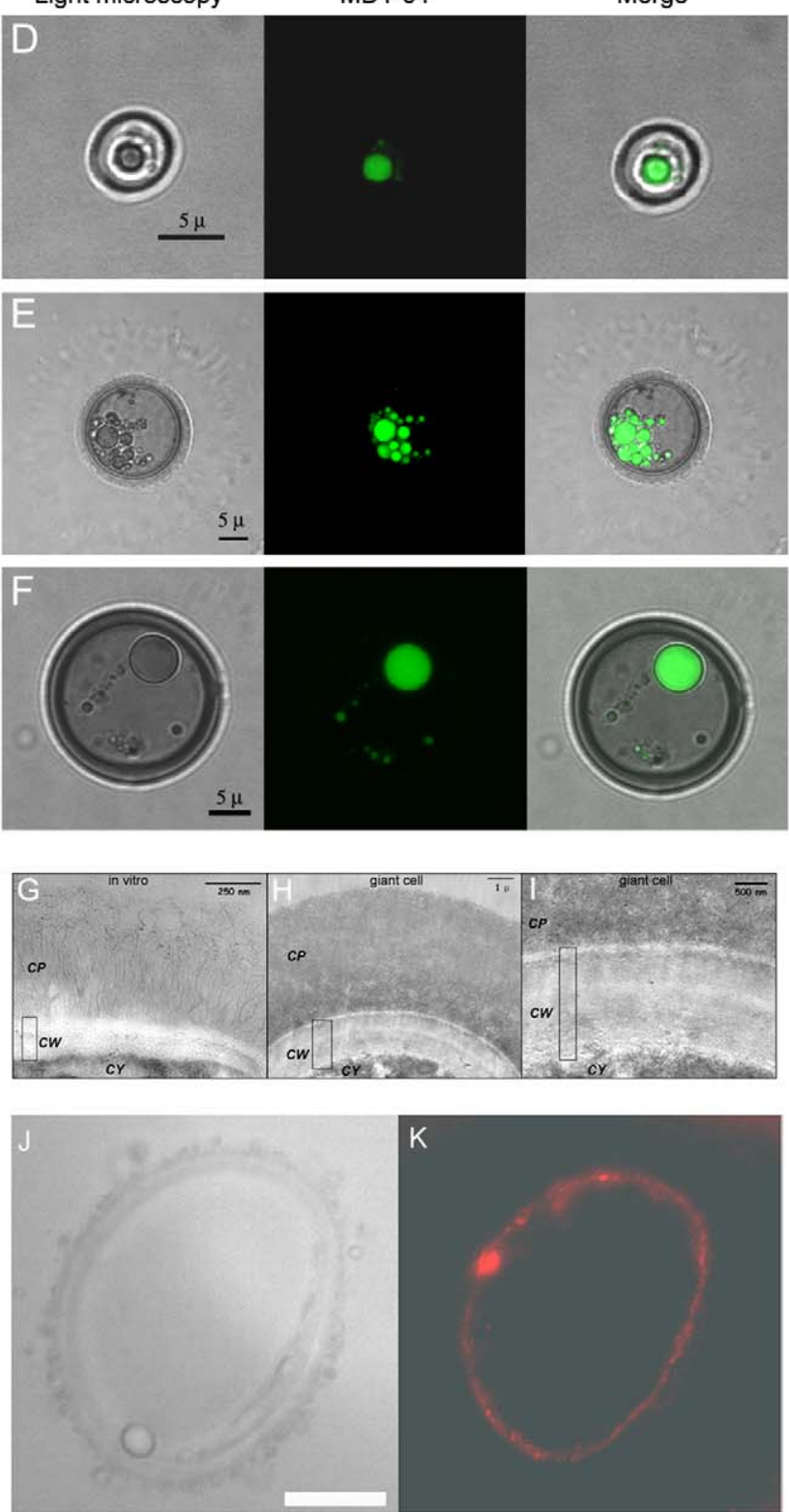

Figure 1. Morphological features of giant cells from infected mice. A) Cells grown in vitro in Sabouraud medium. B) Cell obtained from the lungs of a mouse infected with $C$. neoformans $\left(10^{5}\right.$ cells/mouse) 5 weeks earlier. C) Photomicrographs of a giant cell illustrating the presence of multiple vesicles (highlighted with arrows) within giant cells. Scale bar, $10 \mu \mathrm{m}$. D, E and F, vacuole staining with MDY-64 dye. Yeast cells isolated from the lung of mice four weeks after infection with $10^{5}$ yeast cells were stained with the specific vacuole marker MDY-64 as described in Materials and Methods. Localization of the signal was performed by confocal microscopy. D) Cell of regular size. E and F) Giant cells. In all the cases, regular light microscopy, fluorescence and the merge of both images are shown. Scale bars in the left panels applies to the corresponding middle and right panels. G, H and I, transmission electron microscopy of the capsule and cell wall of regular and giant cells.
Cells grown in vitro or giant cells obtained from the lungs of mice three weeks after infection were fixed and processed for TEM. G, cell grown in vitro; $\mathrm{H}$, giant cell; I, magnification of the cell wall region of the giant cell shown in $\mathrm{B}$. $C P$, capsule; $C W$, cell wall; $C Y$, cytoplasm. The rectangle indicates the width of the cell wall. J,K, staining of giant cells with antimelanin mAb. J, light microscopy; K, fluorescence. Scale bar, $10 \mu \mathrm{m}$. doi:10.1371/journal.ppat.1000945.g001

the capsule of giant cells appeared intact and well preserved, revealing a highly cross-linked polysaccharide net (Figure 2B) that accumulated around the cell body as a very compacted layer (Figure 2G). In addition, we frequently observed the presence of "holes" in the capsule (Figure 2 D, E and F), which we interpreted as pathways formed during recent budding. Transmission electron microscopy images confirmed that the capsule of giant cells was denser than the capsule of in vitro cultivated cells (Figure $1 \mathrm{H}, \mathrm{I}$ ).

The higher degree of cross-linking in the capsule of giant cells relative to in vitro grown cells was confirmed by treating the cells with DMSO or $\gamma$-radiation, procedures known to strip the capsule of cells of regular size [29,30,31]. $\gamma$-radiation removed the majority of capsule of giant cells, but the inner region of the capsule remained attached to the cell (Figure 3). In contrast, DMSO treatment did not affect capsular size of giant cells while it routinely strips the capsule of cells grown in vitro (results not shown). The increased resistance of the inner capsule to radiation and the overall capsule to organic solvents is consistent with a higher degree of capsular cross-linking by the giant cells.

In C. neoformans, complement deposition is affected by the porosity and blocking capacity of the capsule [32]. Consequently, we characterized complement localization in the capsule of giant cells as a measure of capsule penetrability. As shown in Figure 4A, complement is known to deposit in the inner location of the capsule near the cell wall of typical yeast cells [20]. When giant cells were incubated in mouse serum, we observed that complement was not detected in the inner regions of the capsule (Figure 4B). The exclusion of complement from the inner capsule is consistent with reduced permeability resulting from increased fibril cross-linking.

To ascertain whether giant cells manifested antigenic differences from cells grown in vitro we used indirect immunofluorescence with $\mathrm{mAb}$ 18B7. We compared cells of different size obtained from the lungs of infected mice, to avoid the possibility that factors of the immune system influenced the antigenic properties of the capsule. When stained with mAbs 18B7, cells of small size exhibited a uniform annular binding pattern (Figure 4C), which was identical to the binding of this $\mathrm{mAb}$ to cells grown in vitro [32]. In contrast, most of the fluorescence localized to the edge of the giant cell capsule, and this binding was diffuse and punctate (Figure 4D-F). Moreover, many cells showed a double ring, punctate pattern, with a more uniform inner ring and a rougher, more diffuse outer ring.

Chitin-like structures in the capsule were recently demonstrated by the specific binding of fluorescent wheat germ agglutinin, which binds to sialic acids and $\beta-1,4-\mathrm{N}$-acetylglucosamine (GlcNAc) oligomers [33]. We used WGA to ascertain whether these structures were also present in giant cells. Cells grown in vitro bound WGA, especially at the neck between the mother cell and the bud (Figure 4G). In giant cells, these structures were particularly prominent. Protrusions into the capsule were longer, reaching several microns (Figure $4 \mathrm{H}$ ).

\section{Replication of giant cells}

Giant cells were viable, since they replicated when placed on fresh agar plates. Daughter cells emerging from giant cells were 

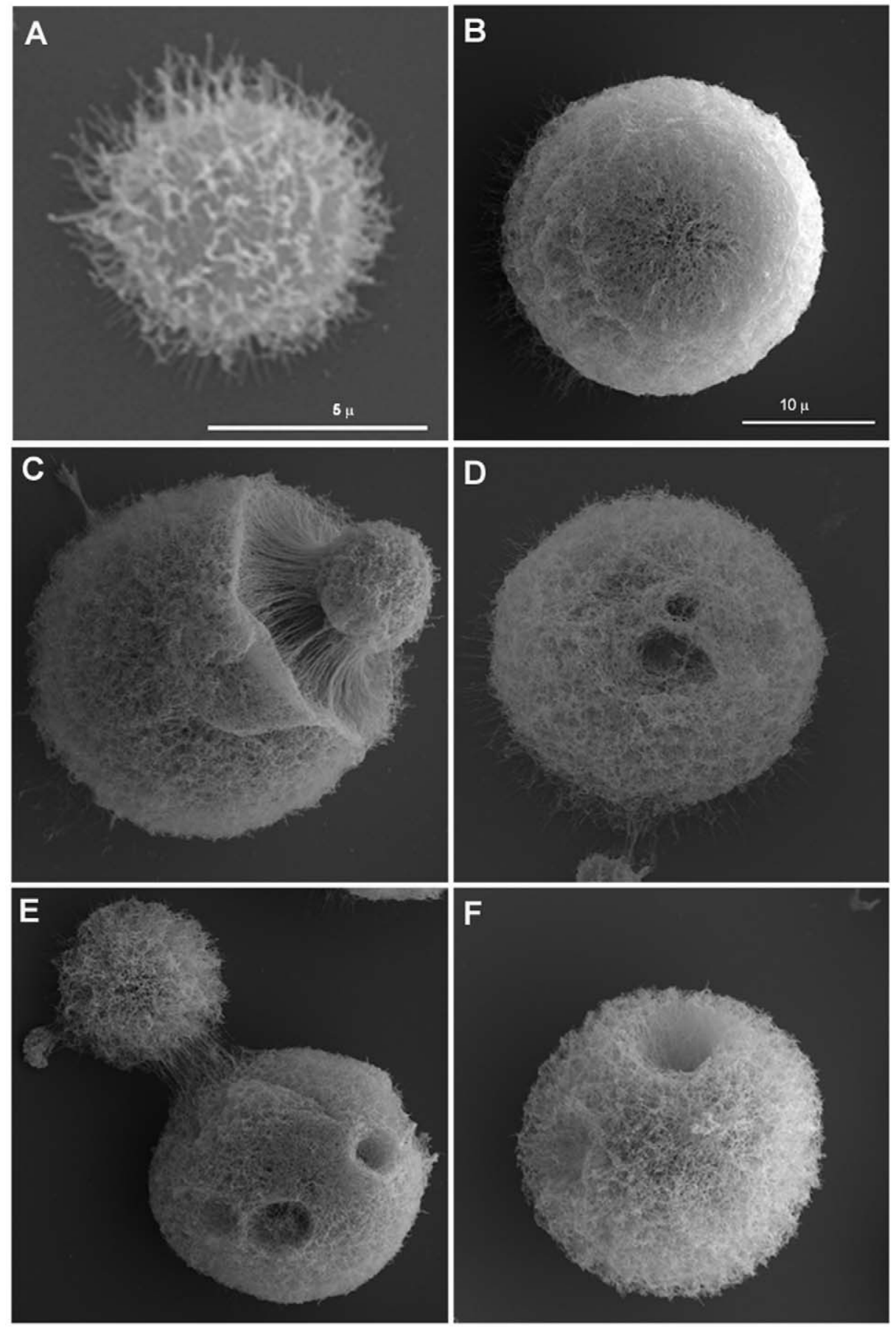

Figure 2. Scanning electron microscopy of cells grown in vitro and of giant cells. A) Cell in vitro grown in Sabouraud. B-F) Giant cells isolated from lung. Scale bar in panel B $(10 \mu \mathrm{m})$ also applies to panels C-F. doi:10.1371/journal.ppat.1000945.g002

not trapped inside the thick polysaccharide capsule, but rather traversed it in less than 0.08 seconds (Figure 5A and B, supporting Videos S1 and S2). In some cells, movement through the capsule was much faster, taking less than 0.01 seconds (Figure 5C, supporting Video S3). By measuring the distance travelled through the capsule by emerging buds and the transit time we estimated that the daughter cells traversed the capsule at $20-50 \mathrm{~m} / \mathrm{h}$, which is a remarkably high velocity for a microscopic unicellular particle in a gelatinous environment.
This data suggested the existence of a motive force propelling and separating the buds from the mother cell's capsule. We observed that giant cells could produce several daughter cells over brief periods of time (2-3 hours), with buds always emerging from the same cell site (data not shown). Despite ejection, the daughter cells remained close to the capsule of the mother cells where they replicated, producing abundant progeny around the giant cells. Even after the giant cells were surrounded by daughter cells, new buds were still ejected with significant force, since they were able 
A

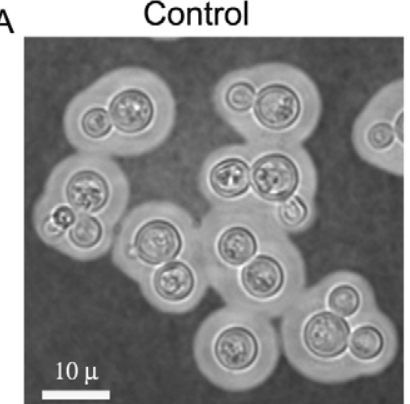

B

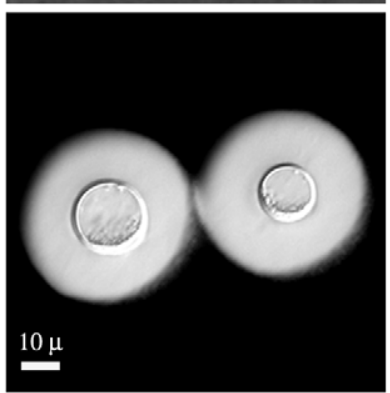

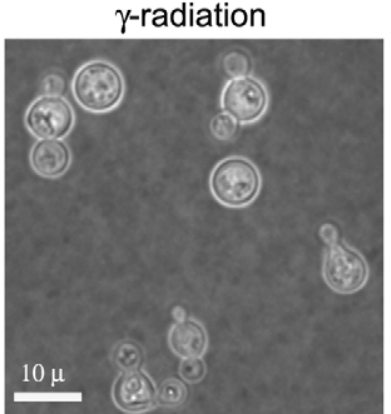

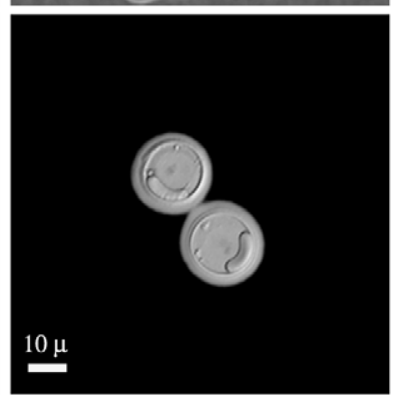

Figure 3. Capsule release by $\gamma$-radiation. Cells of in vitro-enlarged capsule (A) and giant cells (B) were exposed to $\gamma$-irradiation, suspended in India ink, and observed under the microscope. Images of representative cells are shown before (control, left panel) and after irradiation ( $\gamma$-irradiation, right panel).

doi:10.1371/journal.ppat.1000945.g003

to displace and move the surrounding cells upon impact (see supporting Video S4).

When placed on agar, we observed that not all giant cells produced daughter cells after $24 \mathrm{~h}$, suggesting that some of these cells were metabolically arrested, or had died prior to or during the isolation procedure. To measure the percentage of replicating cells we obtained giant cells from two mice and counted the proportion of giant cells producing colonies after $24 \mathrm{~h}$ on agar with a microscope. The percentage of giant cells reproducing was $60 \%$ and $73 \%$ for each mouse, respectively, indicating that the majority of giant cells were viable.

As a secondary technique for testing giant cell viability we used the method based on the reduction of 2,3-bis(2-methoxy-4-nitro-5sulfophenyl)-2H-tetrazolium-5-carboxanilide inner salt (XTT) by alive cells. Giant cells manifested a strong capacity to reduce XTT, which was approximately 100 -fold greater than the activity shown by the same number of cells grown in vitro (data not shown). This result indicates that giant cells are metabolically active.

\section{In vitro cellular growth in minimal media and its relation to cell aging}

We tried to induce giant cell formation in vitro by incubating the cells in different media. When we incubated the cells in minimal media, around $4-5 \%$ of the cells showed a marked increased in cell size over 4 days. These cells reached up to 25$30 \mu \mathrm{m}$ in diameter (capsule included), approximating, but not quite reaching the size of the giant cells recovered from mouse lungs. In addition, these in vitro giant cells showed other phenotypic differences with the giant cells obtained in vitro, such a smaller capsular size and a lack of enlargement of the cell wall (result not shown). Although this in vitro medium only partially reproduced the gigantism phenomenon, we used it to study if there was any relationship between cellular enlargement and the age of the cells. We hypothesized that massive cellular growth required a

prolonged period of time, so the majority of the giant cells obtained would be originated from the initial inocula. To explore this hypothesis, we labelled the cells with complement. Complement proteins, especially C3, bind to the capsule covalently without inhibiting cell growth and do not segregate to buds after replication [34]. Consequently, we labelled cells grown in Sabouraud medium with mouse C3 and then incubated them in minimal medium (which induces a small population of giant-like cells) and Sabouraud medium. At time zero, all the cells were labelled with complement (Figure 6A), but after 4 days of incubation in minimal medium, only a few cells remained labelled (Figure 6B). When we measured the average size of the cells with complement bound after four days of incubation in minimal medium, we found that these cells had a significant larger size than the cells incubated in Sabouraud medium (Figure 6B). We repeated this experiment, placing the cells in parallel in minimal medium, which induces cell enlargement in some cells, and in Sabouraud medium, in which cell enlargement is not expected. Then, we measured cell size of complement-labelled and nonlabelled cells. In minimal medium, we observed that the complement-stained cells were significantly larger than the unlabelled population (Figure 6C, D). Large cells were not found in Sabouraud medium after C3 labelling and there was no difference in the size of cells with and without C3 labelling (Figure 6C, D). This result indicates that cellular enlargement and giant cell formation is correlated with the age of the cells, such that the giant cells are the older cells in the culture.

\section{DNA content}

We hypothesized that giant cell formation was a consequence of continued cell cycle progression without cellular fission. In other fungi, cell size can be related to DNA content [35,36]. Using flow cytometry to measure DNA content, we found that giant cells had low permeability to propidium iodide by regular staining protocols (results not shown), but could be permeabilized by heating at $60^{\circ} \mathrm{C}$ for 45 minutes. As mentioned above, cells from the lungs of mice infected for 3-4 weeks showed strong autofluorescence, so we measured the intensity of the signal in the presence or absence of propidium iodide. We first analysed the difference in the forward scatter (FSC, cell size) and side scatter (SSC, cell complexity). When we compared these parameters, we observed a population of larger yeasts in the cells isolated from the lung that was not present in the yeast cells obtained in vitro, as was expected with the presence of giant cells in vivo (Figure 7A, B). This population was defined as region 1 (R1), which contained the giant cells present in the population. To estimate the DNA content, we added propidium iodide to these samples. When we measured the propidium iodide staining, we found that there was a high variation in the DNA content in the cell population obtained from lungs (Figure 7C), which implied a high variation in the DNA content of cells in vivo. Fungal cells isolated from the lungs of infected mice also displayed significant autofluorescence in the absence of propidium iodide staining. To assess the staining of giant cells, we subtracted the autofluorescence of the cells present in region 1 from the fluorescence value determined in the presence of propidium iodide. The mean fluorescence intensity for the giant cells was almost $10^{3}$ fold higher than the signal measured in cells grown in vitro (Figure 7D). This result suggested that giant cells contain multiple copies of DNA. To quantify the ploidy level of the giant cells further, we performed real time PCR to amplify the ITS1 region from ribosomal DNA. We included controls of purified genomic DNA of known concentrations, which yielded a lineal relationship between crossing point values and DNA concentration. When we compared 300 giant and regular cells 

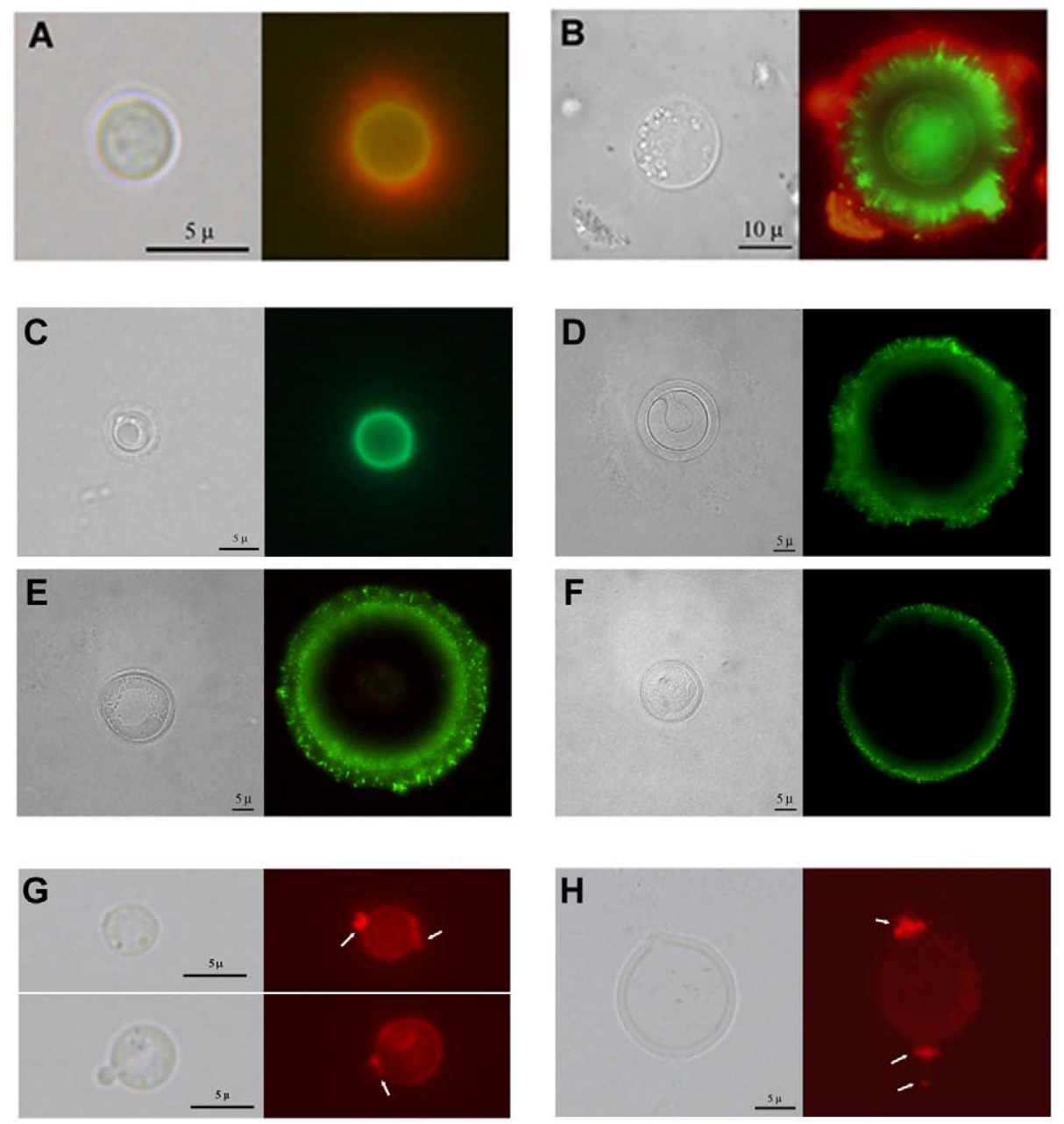

Figure 4. Differences in capsular structure between regular and giant cells. Yeast cells from lung extracts were incubated in mouse serum and labelled with antibodies to C3 and GXM. A) cell of a regular size; B) giant cell. Light microscopy and complement localization (green fluorescence) and capsule edge (red fluorescence) are shown. C-H) capsular features shown by fluorescence. C-F) Indirect immunofluorescence with GXM-binding mAbs. MAb $18 B 7$ labelling of cells of regular size (C) or giant cells (D-F) isolated from lung of infected mice. Light microscopy and fluorescence pictures are shown for each cell. G-H) Binding of wheat germ agglutinin to C. neoformans. The presence of chitin-like structures in the capsule was studied by the binding of WGA to the cells as described in Materials and Methods. G) Cells grown in Sabouraud and then transferred to 10\% Saboraud buffered at $\mathrm{pH} 7.3$ with $50 \mathrm{mM}$ MOPS buffer to induce capsule enlargement. H) A representative giant cell isolated from the lungs of infected mice. Arrows indicate the major regions where WGA binds to the cells. Scale bars in C-D in light microscopy panels denote 5 microns and apply to the fluorescence images. doi:10.1371/journal.ppat.1000945.g004

there was a difference in the $\mathrm{Ct}$ values of more than 3 cycles (36.95 in giant cells versus 40.00 in regular in vitro grown cells). When we estimated the amount of DNA present in each condition according to a standard curve generated using different concentrations of genomic DNA, we calculated that the amount of DNA in each giant cell was $1.3 \times 10^{-7} \mathrm{ng}$. In contrast, in vitro cultivated cells contained $8.4 \times 10^{-9} \mathrm{ng}$. This result indicated that giant cells contained $16 \times$ DNA than regular cells. This experiment was repeated using different cell concentrations and consistent results were obtained (result not shown).

DAPI was used to directly observe the nucleus of the giant cells. This staining revealed that both regular (Figure 7E) and giant cells (Figure 7F) contained a single nucleus.

\section{Signal transduction pathways involved in giant cell formation}

We investigated the potential involvement of two of the major signal transduction pathways in C. neoformans (cAMP and Rasl [37,38]) in giant cell formation. Rasl-deficient cells produced giant cells in the lungs of infected mice (Figure 8A). In contrast, mutants unable to accumulate cAMP (lacking adenylate cyclase encoded by the CAC1 gene) did not produce giant cells during murine infection (Figure 8A), suggesting that this pathway was required for giant cell formation.

The absence of giant cells in mice infected with the cAMP mutant was associated with a reduced fungal burden. Hence, the lack of giant cells with this mutant in vivo might be related to the ability of the host to rapidly clear the fungus. For this reason, we examined whether a cac1 mutant formed giant cells in minimal media. The cac1 mutant failed to produce giant cells, whereas a significant proportion of cells of the wild type (H99) and reconstituted (cac1/CAC1) strains manifested cellular enlargement (Figure 8B), confirming that cAMP pathway is involved in giant cell formation. To further characterize this phenotype, we analysed the forward and side scatter profile of the cells from the three strains by flow cytometry, since this type of plot allows for clear differentiations in cell size. As shown in Figure 8C, the cac1 
A

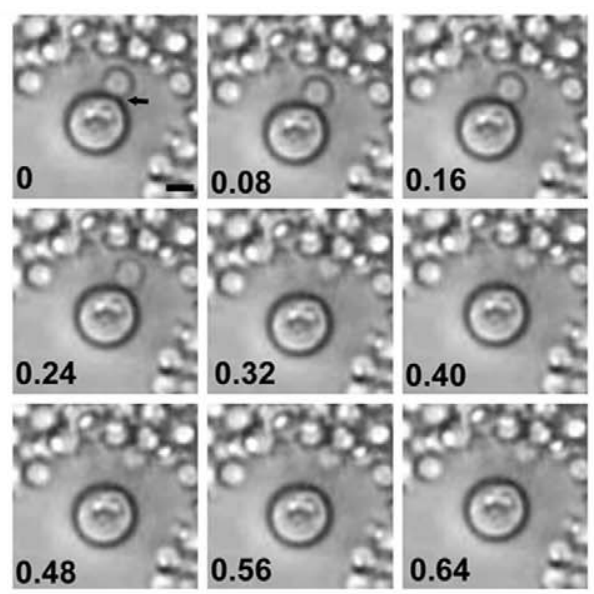

B
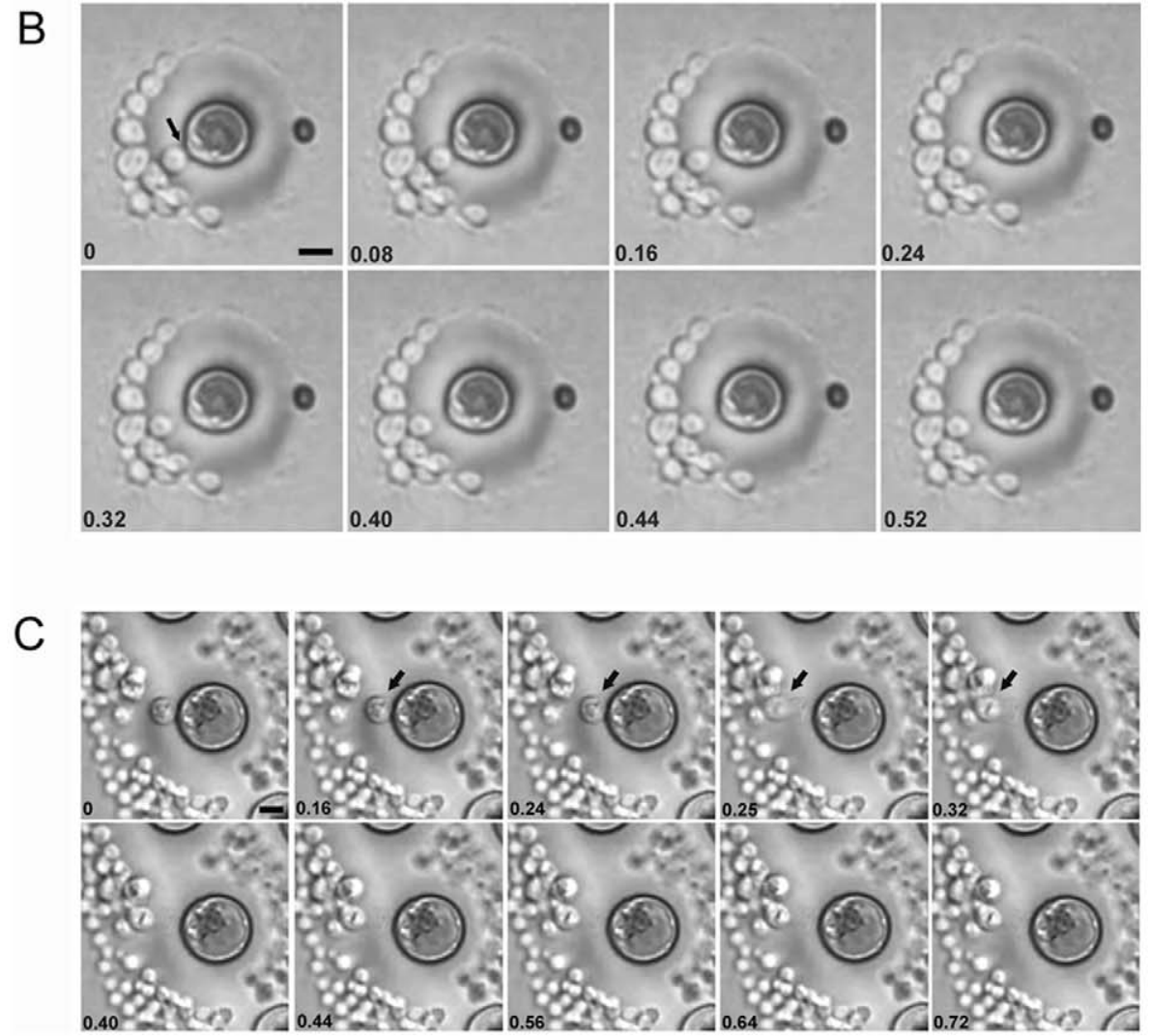

Figure 5. Time lapse images of replicating giant cells in vitro. Giant cells were obtained from lungs of four weeks-infected mice and placed on Sabouraud plates. After $18 \mathrm{~h}$, the growing colonies were monitored under the microscope. The digital videos were processed with Windows Movie Maker software. This software allowed the conversion of the videos into single pictures, each one represented as a different frame of the video. The number in each picture corresponds to the time in seconds. A, B and C correspond to three different budding events. Corresponding videos are included as supporting information files. doi:10.1371/journal.ppat.1000945.g005

mutant yielded a very homogenous population of relatively small FSC and SSC values. In contrast, the wild type and reconstituted strains produced more heterogeneous populations, in which cells with larger FSC and SSG values were measured, indicating the appearance of cells of larger size.

\section{Distribution of fungal cell size during infection and correlation with inflammation}

The distribution of cell sizes in vivo was extremely variable depending on the experimental conditions. Under our standard conditions (infection of 6-8 weeks old mice with $10^{5}$ yeast cells) we consistently found that the proportion of giant cells in the lung was between $1-10 \%$, with variation between individual mice and between experiments. However, in several experiments, we occasionally found that the proportion of giant cells was higher than $90 \%$ of the lung fungal cell population. Curiously, in those experiments where the proportion of giant cells was very high, there were no obvious signs of disease and the mice looked healthy. We decided to investigate this observation in more detail by studying the relationship between inoculum and giant cell 

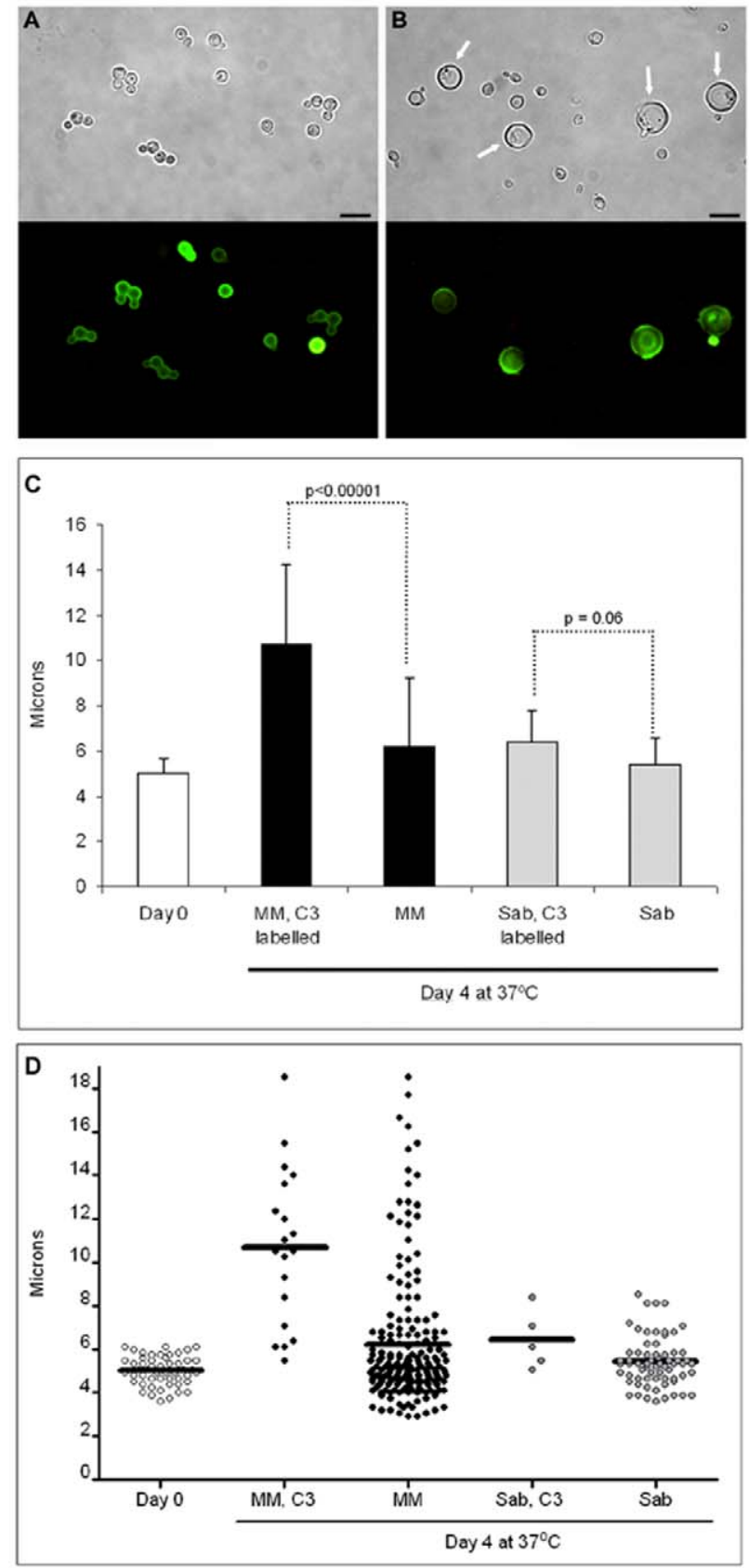

Figure 6. Giant cell formation in vitro. Cells from H99 strain were grown in Sabouraud, washed and labelled with mouse serum. C3 deposition was then detected by immunofluorescence (A). After incubation in mouse serum, cryptococcal cells were transferred to minimal medium (MM) for four days, and C3 was detected (B). Scale bar in $A$ and $B, 10 \mu \mathrm{m}$, and apply to the corresponding fluorescence panels. C) Cells were grown and labelled as in A (Day 0 sample), transferred to Sabouraud or MM for 4 days at $37^{\circ} \mathrm{C}$, and the cell size was measured in the C3 labelled population ("MM, C3 labelled" and "Sab, C3 labelled") and in the whole population, including both $\mathrm{C} 3$ labelled and unlabelled cells. The average and the standard deviation (error bars) are plotted and $p$-values for the highlighted comparisons are shown. At least, 2050 cells were counted, except in the "Sab, C3 labelled" samples, where C3 positive cells were rarely identified due to the overgrowth of the culture. Kruskall-Wallis test was used to assess statistical differences. D) Scatter representation showing all the cells plotted in panel B. The line in each sample denotes the average of the distribution. doi:10.1371/journal.ppat.1000945.g006 formation. We hypothesized that infections with low inocula could reproduce chronic or latent asymptomatic infections. For this purpose, we performed infections with high $\left(10^{6} /\right.$ mouse) or a low dose $\left(10^{4}\right.$ cells/mouse).

Mice infected with high inocula consistently developed typical cryptococcal disease, as indirectly shown by progressive weight loss (Figure 9A). However, we found a high variation in outcome when the mice were infected with a low inoculum. Most of these mice $(2$ of 3) developed disease comparable with that seen after infection with a high dose. Severe disease was characterized by dense inflammation in the lungs, increasing the size and weight of these organs (1.3-1.8 grams) such that they accounted for 7-8\% of the total body weight (Figure 9B). In contrast, the lung mass of asymptomatic mice (control mice and one of the mice infected with low inocula) was approximately 0.45 grams and $\sim 1 \%$ of total body weight. As expected, mice developing severe disease had a significantly higher number of CFUs $\left(>10^{6} / \mathrm{lung}\right)$ than the mice that did not manifest obvious signs of disease, where the number of CFUs remained very low $\left(<10^{4}\right)$ during the experiment (Figure 9G). When we recovered the fungal cells from the lungs of these mice, we found profound differences in the size of the yeast cells. The average cryptococcal cell size in mice receiving a high inoculum was around $15-20 \mu \mathrm{m}$, which was significantly larger than the size reached when grown in vitro in rich medium (Figure 9D, Sabouraud medium). Although approximately 5-20\% of the yeast cells met criteria for giant cells, the enlargement of the majority of cells isolated was mainly due to increase in the capsule size, so the size of these populations was only slightly different from the size reached when capsule size is induced overnight in vitro (see Figure 9D, in vitro enlarged capsule size). We were able to isolate around $1-3 \times 10^{3}$ C. neoformans cells from the lungs of asymptomatic, low dose infected mice and the average yeast cell size was around $40 \mu \mathrm{m}$ (Figure 9D). Notably, approximately $70 \%$ of the isolated yeast cells were giant forms.

We also analysed the proportion of giant cells in the lungs using Classification and Regression Trees (CART) analysis. Using this approach, we found that there was a strong association between the total fungal cell size in the lungs and the degree of inflammation, such that high inflammation was predicted when the average fungal cell size was below $36 \mu \mathrm{m}$ (Figure 9E). This prediction is in accordance with our initial criteria of defining giant cells as those with a cell diameter greater than $30 \mu \mathrm{m}$. When we plotted the corresponding ROC curve, we found that the region under the curve was 0.80 , which provides strong support for the prediction. On the other hand, the model could not efficiently predict the proportion of giant cells according to inflammation, due to the low number of yeast cells found in lungs without significant inflammation.

The relationship between the proportion of giant cells and inflammation was confirmed histologically. In control mice, the lungs revealed the typical structure in which alveolar spaces were present throughout the lungs (Figure 10). In the infected mice, we only observed this benign histology in the asymptomatic mouse (mouse 1 of the group infected with $10^{4}$ yeast cells, Figure 10). In the rest of the low dose (Figure 10) and all of the high dose infected mice (result not shown), dense inflammation was observed and alveolar spaces contained numerous yeast cells and inflammatory cells.

We performed another experiment using older mice (14-16 weeks old), which are more resistant to infection, and a lower infective dose than in the experiment previously described. We infected with either a low $\left(10^{3}\right.$ cells/mouse, 10 mice $)$ or a high dose $\left(10^{5}\right.$ cells/mouse, 3 mice $)$, and measured fungal cell size after a month of infection. In this new model, the mice did not develop 

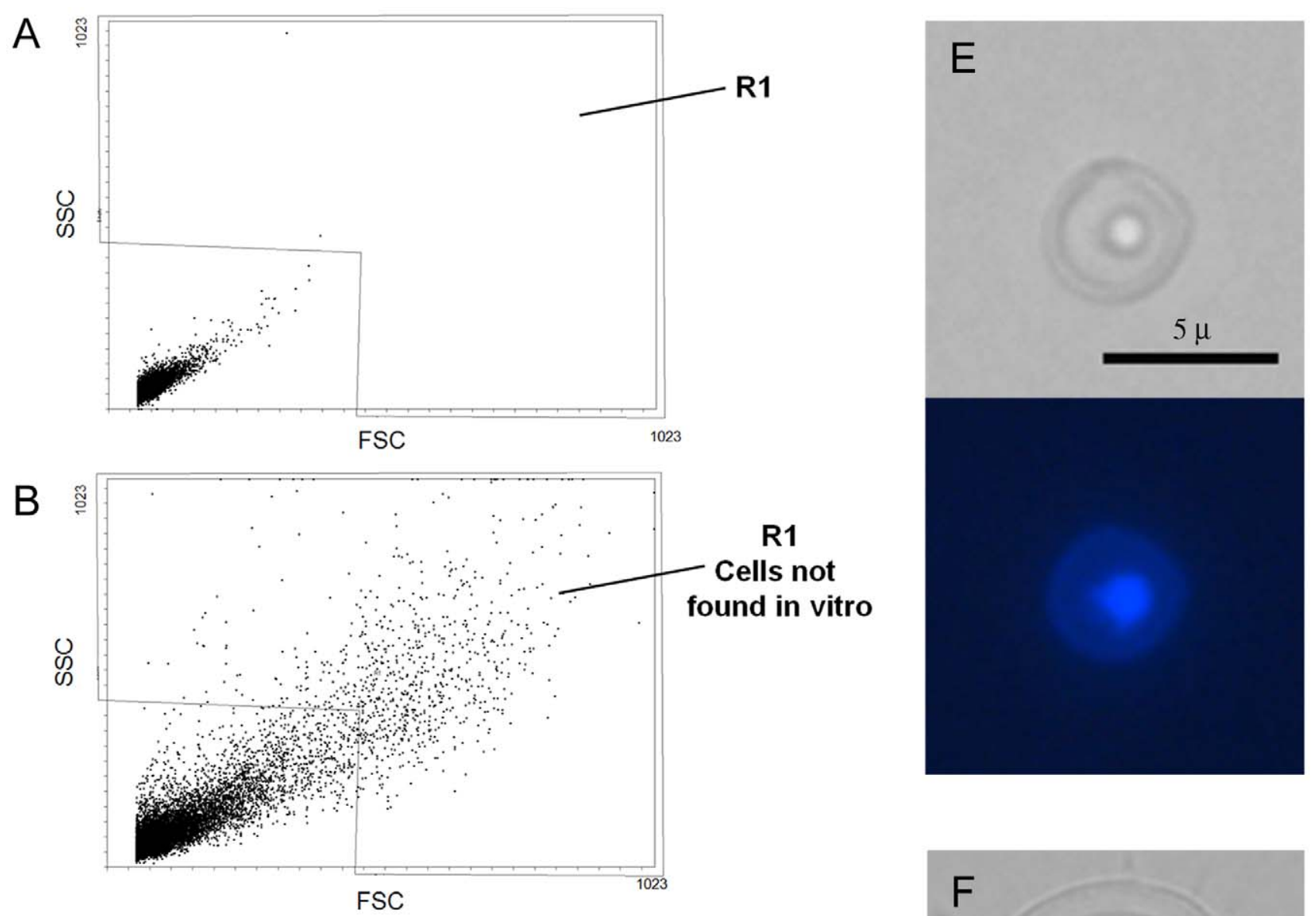

R1

Cells not found in vitro
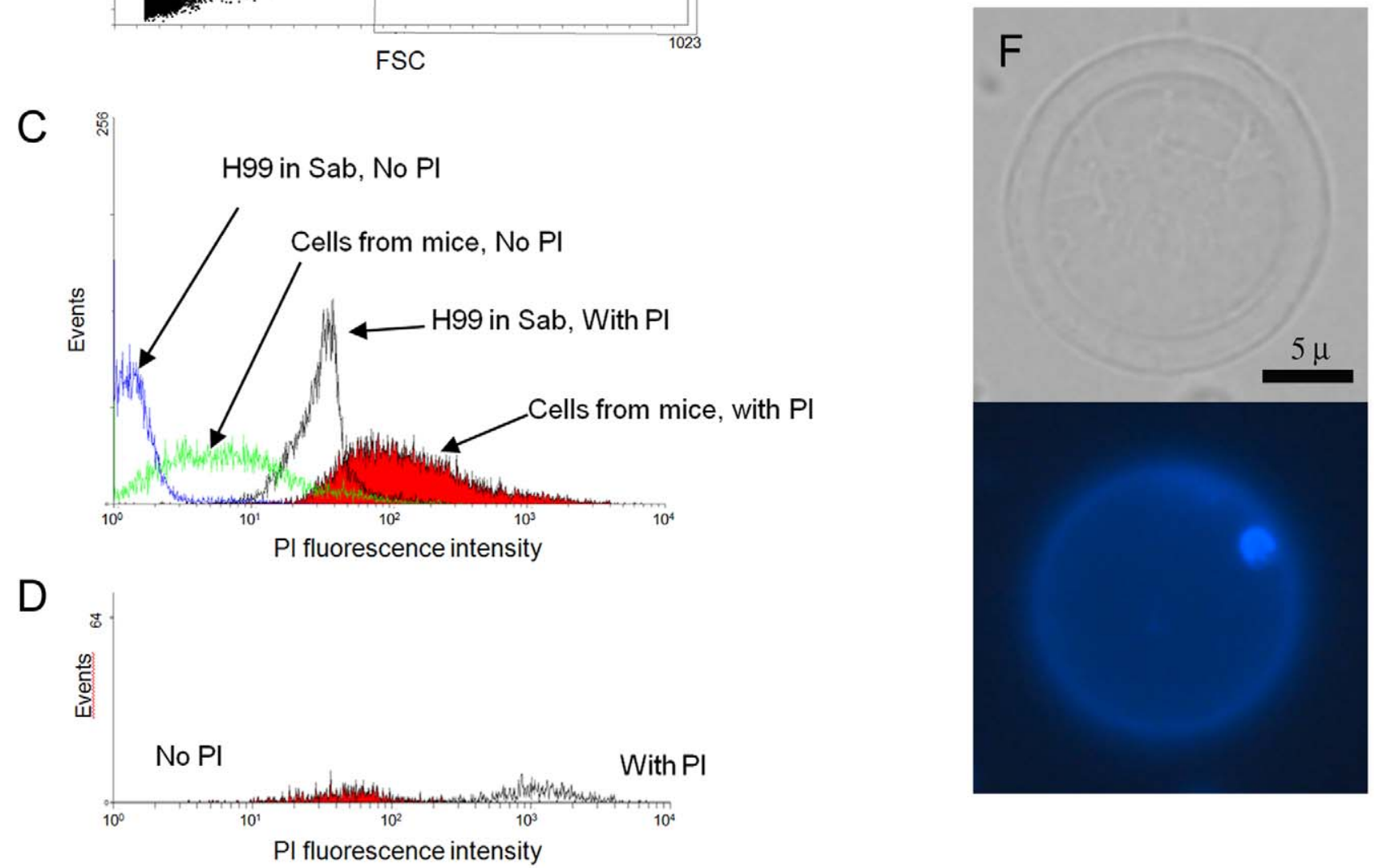

Figure 7. Determination of DNA content by cytometry and DAPI staining. Fungal cell samples were obtained from the lungs of one mouse 3 weeks after challenge with $10^{5} \mathrm{C}$. neoformans cells. As a control, cells grown for 24 hours in Sabouraud were also used. The cells were fixed after incubation at $60^{\circ} \mathrm{C}$ for 45 minutes. Propidium iodide was immediately added at $10 \mu \mathrm{g} / \mathrm{mL}$ DNA content and the labelling was determined by the propidium iodide fluorescence intensity. Matched samples were subjected to cytometry without propidium iodide. A) FSC/SSC plot of cells grown in 
Sabouraud. B) FSC/SSC of cryptococcal cells from lungs. Region 1 delimits all the cells whose size and complexity are not found in cultures grown in vitro and presumably cover all the cells with increased cell size. C) Propidium iodide fluorescence intensity of the four samples analyzed: in vivo isolated cells (plus and minus propidium iodide) and in vitro cells (plus and minus propidium iodide). D) Propidium iodide fluorescence intensity of the cells from the lung present in R1. E-F) DAPI staining. Yeast cells obtained from the lungs of mice infected with $10^{5}$ yeast cells were stained with DAPI. E) cell of regular size; F) giant cell. Corresponding light microscopy and fluorescence images are shown. Scale bar in the light microscopy panels apply to the fluorescence images.

doi:10.1371/journal.ppat.1000945.g007

any visible sign of disease. When the mice were sacrificed after one month, only one of the mice infected with the high dose showed inflammation in the lungs (table $1,10^{5}$, mouse 2). In the group infected with low dose, we did not find yeast cells in 3 mice, indicating that the infection had been cleared. In the other seven mice, we found a low number of yeast cells, suggesting a chronic asymptomatic infection. In six of the seven mice, the average size of the fungal cells was above $30 \mu \mathrm{m}$, and the proportion of giant cells was between $50-90 \%$. When the mice were infected with a higher dose, the two mice in which no inflammation was detected showed fungal cell sizes above $30 \mu \mathrm{m}$, with a proportion of giant cells around $70-80 \%$. In the mouse with inflammation (mouse number 2), the average fungal cell size was smaller $(14 \mu \mathrm{m})$, and the proportion of giant cells was less than $5 \%$. This data supports the notion that the highest proportion of giant cells is found in hosts with chronic and longstanding infection.

\section{Susceptibility to oxidative stress}

We measured the susceptibility of giant cells to oxidative stress produced by incubation in $\mathrm{H}_{2} \mathrm{O}_{2}$. Giant cells were significantly more resistant to killing by oxidative stress than cryptococcal cells grown in vitro, with survival rates of $19 \% \pm 10$ and $46 \% \pm 14$ for cells grown in vitro and giant cells, respectively $(p=0.014)$.

\section{In vitro interaction of giant cells with phagocytic cells}

To further characterize the interaction of giant cells with host effector cells, we incubated macrophage-like cells with giant cells and observed the outcome of the interaction using live-imaging microscopy. When small-sized cryptococci were exposed to macrophages, we observed rapid and avid phagocytosis, yeast cell transfer between macrophages, fusion of infected macrophages after division, and intracellular replication of the C. neoformans cells, as described previously $[39,40,41,42,43]$ and shown in supporting Videos S5, S6 and S7. None of these phenomena were observed when macrophage-like cells were exposed to $C$. neoformans giant cells, indicating that the interaction between these fungal cells and macrophages was different and had different outcomes. Although in some cases the macrophages seemed to adhere to the giant fungal cells, there was no phagocytosis or macrophage fusion after division (supporting Videos S8 and S9), indicating that macrophages could not cope with the giant cells.

\section{Discussion}

Cryptococcus neoformans giant cells have been occasionally described in the literature primarily as curiosities in histological tissue sections $[22,23,24]$, but their importance in pathogenesis has remained obscure. Apart from the fundamental problems in cell biology posed by the mechanisms responsible for the transition to gigantism, we considered that the presence of fungal giant cells would pose a major problem for the immune system simply by virtue of their size.

Giant cell formation was associated with several changes to the capsule relative to the typical cells observed in vitro. These changes represented an exaggerated response in capsule, cell body, and cell wall size during infection. Moreover, the resistance to capsule shedding after $\gamma$-radiation exposure suggests a more compact and dense structure. Such an increase in capsular compactness could confer a survival advantage in vivo since the capsule is known to protect against oxidative fluxes of the types produced by immune effector cells [21]. Consistent with this idea, we have observed that giant cells are more resistant to oxidative stress.

Giant cells maintained their enormous size ex vivo, although they produced smaller cells in agar at replication rates similar to those observed in vitro. Another remarkable aspect of the budding process is the rapidity with which the buds traversed the capsule, especially considering the denseness and compactness of the polysaccharide noted by scanning and transmission electron microscopy. However, we did observe holes in the capsules of giant cells with dimensions that approximated the size needed for daughter cells to emerge. Similar capsule holes have been occasionally described in encapsulated cells grown in vitro [44]. The strong binding of WGA to these cells also suggests the presence of chitin-like structures, which have been proposed to be involved in the movement of the bud through the capsule of the mother cell [33]. Given prior work noting tunnel-like structures formed around buds $[33,34]$, it is possible that the rapid egress of buds from the mother cells represent movement along such structures that provide a nonobstructed conduit through the capsule.

The cellular mechanisms by which cryptococcal cells enlarge to gigantic sizes are not known and a complete understanding of this phenomenon is beyond the scope of the current work. Nevertheless, we explored the potential mechanism of cell division without fission as a way for progressively increasing mass. Cell growth is intimately dependant on the cell cycle. The cells need to reach a critical size for cell cycle to progress, and there is a constant ratio between the mass of the cell and its DNA content (reviewed in $[45,46,47,48])$. In plants, the phenomenon is striking, because their cells can enlarge in size by 100- or even 1000-fold, and this is achieved by endoreduplication, which is the process in which the cell increases the ploidy of the cells through several rounds of DNA replication [49]. Recently, it has been shown that bacteria from the genus Epulopiscium, which grow to lengths of 200-300 $\mu \mathrm{m}$ and widths of 40-50 $\mu \mathrm{m}$, have extreme polyploidy, generating tens of thousands of copies of their genome [50]. In a process that may be relevant to cryptococcal gigantism, there are some symbiotic bacteria that undergo an important differentiation process achieved by genome amplification by endoreduplication in plant nodules resulting in significant cell enlargement [51] and provide beautiful examples of how some factors of symbiotic plants regulate the cell cycle of their symbiotic microorganisms.

We hypothesized that giant $C$. neoformans cells achieved their size by repeatedly entering G1 cycles without dividing. To investigate this possibility we stained cells for DNA. Cells recovered from infected animals produced a noisy FACS profile that was interpreted as being consistent with cell-to-cell variation in DNA content. By analyzing cell size and fluorescence intensity we showed that cell size correlated with DNA content, thus establishing that larger cells have more DNA, a result confirmed by real-time PCR. These findings are consistent with a mechanism for DNA replication without cell fission. 
A
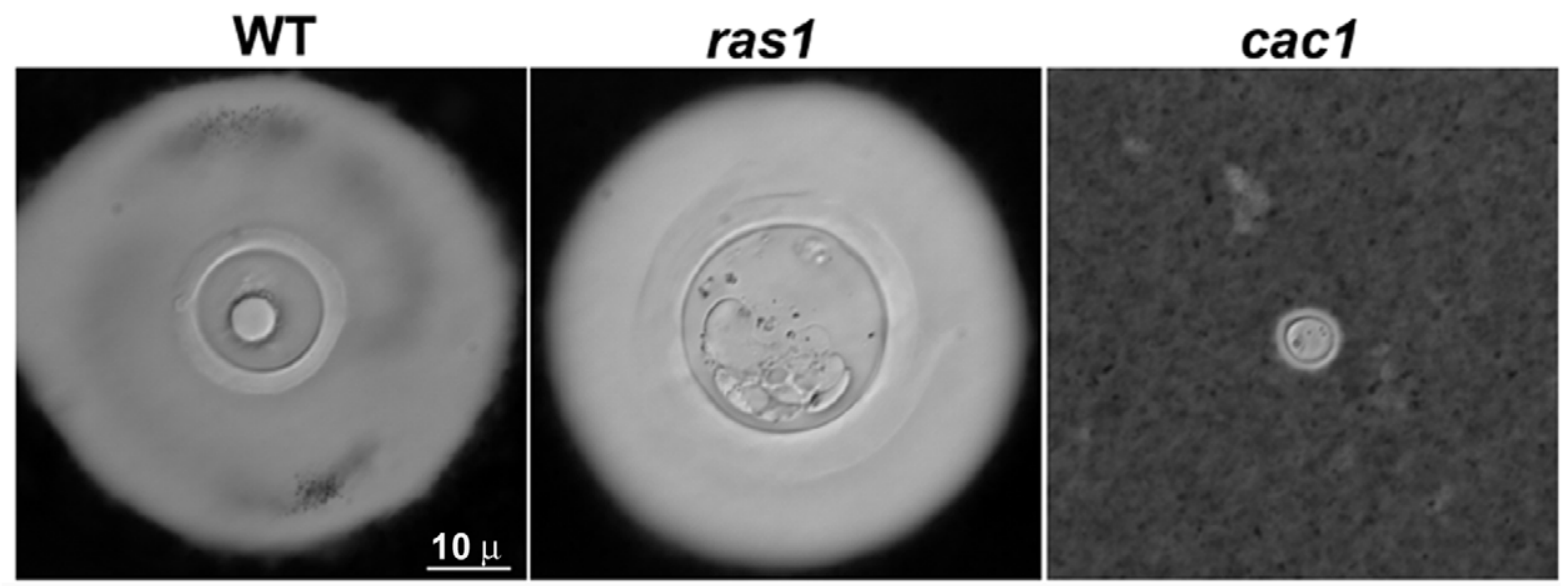

B
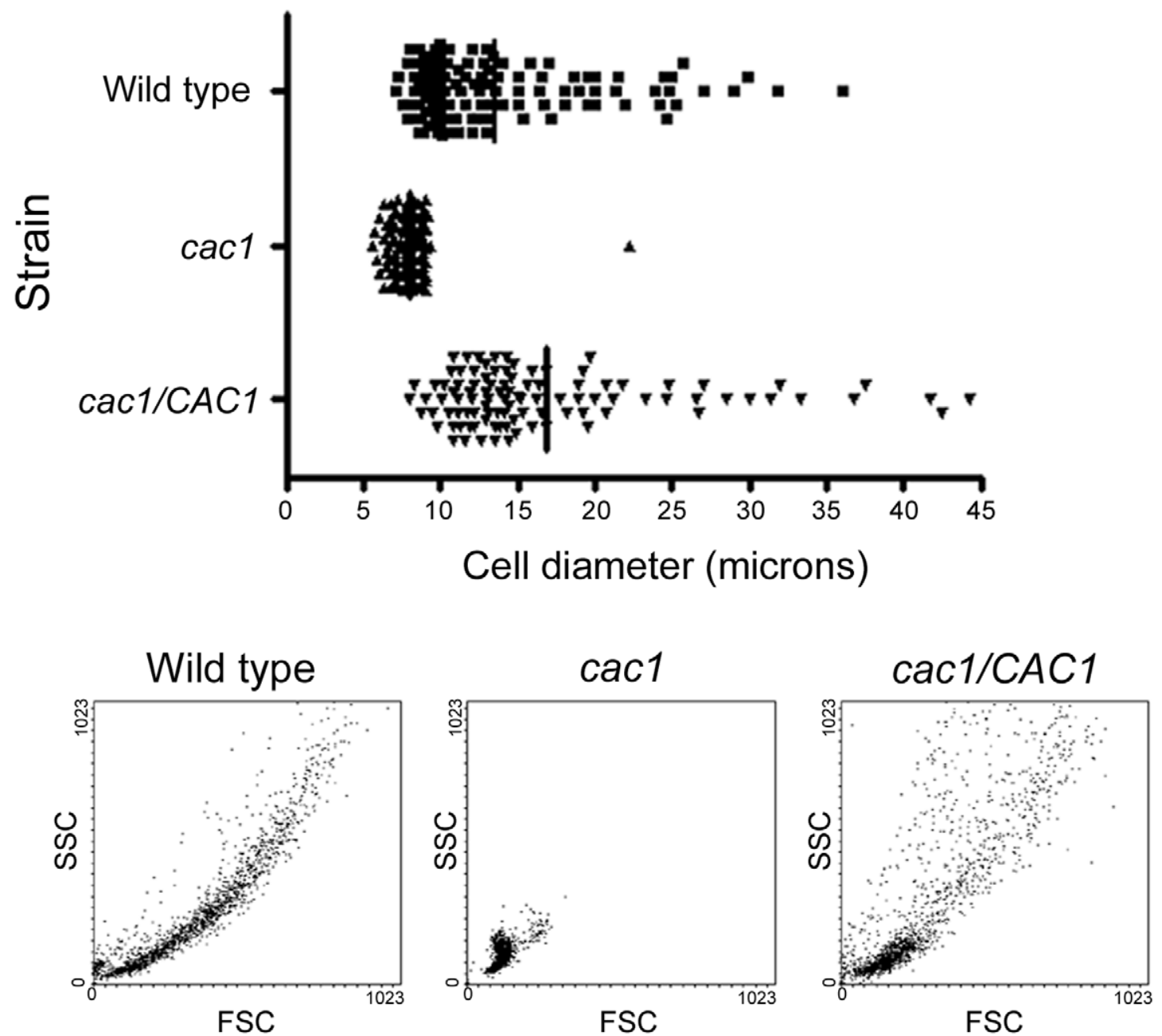

Figure 8. Giant cell formation depends on CAMP, but not Ras1. C57BL/6J mice were infected with H99, ras1 (Ras 1 mutant) and cac1 (adenylate cyclase mutant) strains $\left(10^{6}\right.$ per mouse). After three weeks, the mice were sacrificed and fungal cells were isolated. Representative pictures of fungal cells are shown. A) India ink microscopy, scale bar in left panel applies to all the pictures. B) Cell size distribution of wild type, cac1 mutant and its reconstituted strain (cac1/CAC1) after 5 days of growth in minimal medium at $37^{\circ} \mathrm{C}$. The cells were suspended in India Ink to delimit the capsule, and the diameter of the cells (capsule included) was measured microscopically. C) Forward Scatter/Side Scatter plot of cac1 mutants after incubation in minimal medium. The cells described in B were analysed by flow cytometry to obtain the corresponding forward scatter (FSC, correlated with cell size) and side scatter (SSC, correlated with cell complexity).

doi:10.1371/journal.ppat.1000945.g008 

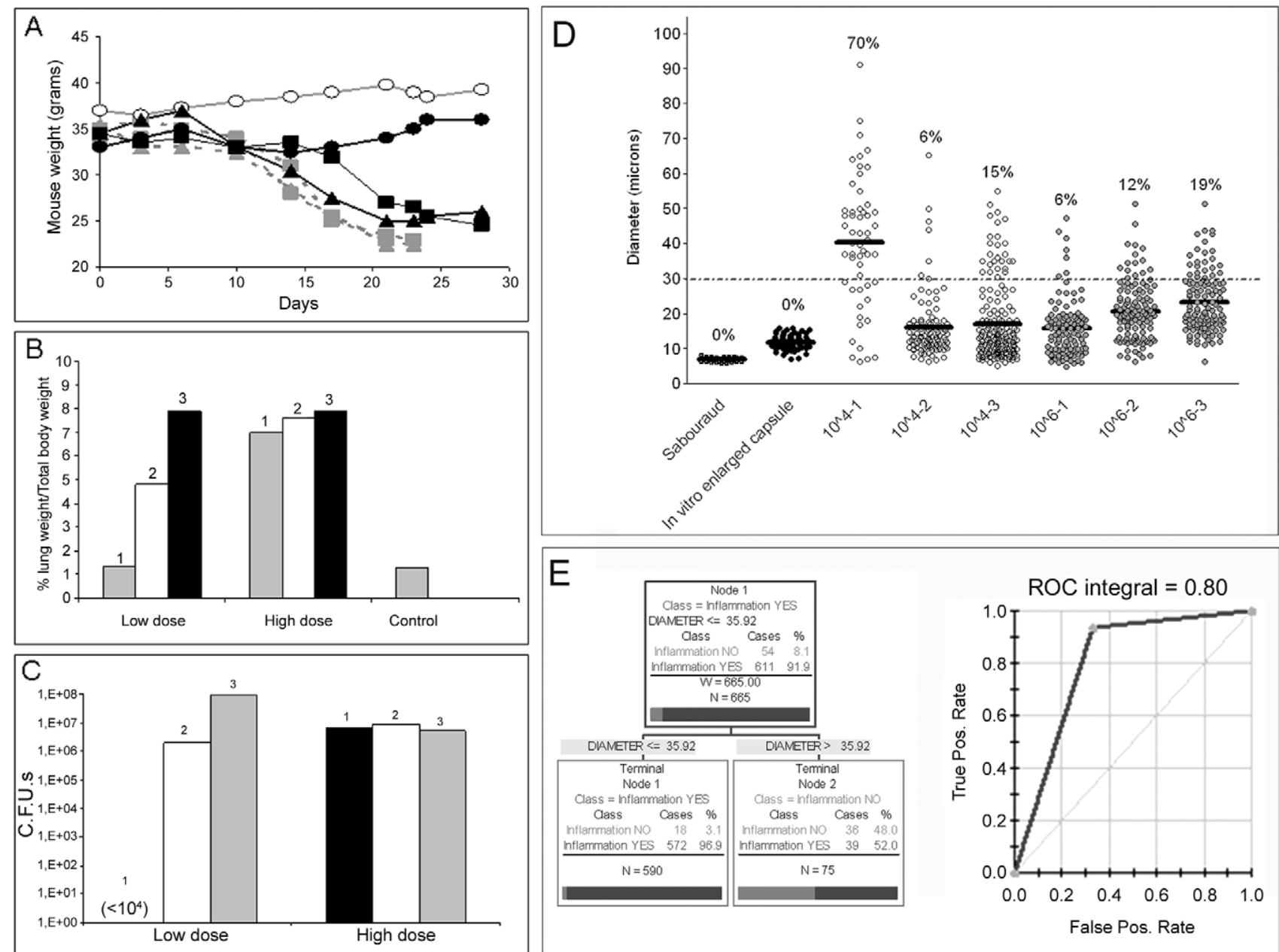

Figure 9. Parameters of disease in mice infected with $C$. neoformans and giant cell proportion in the lungs. CD1 mice were infected with different inocula of $C$. neoformans, and different parameters were monitored during the course of the infection. A) Body weight of mice infected with a low dose $\left(\sim 10^{4}\right.$ cells, black line, closed symbols, $\left.n=3\right)$ or a high dose $\left(10^{6}\right.$, grey line, grey symbols, $\left.n=3\right)$ of $C$. neoformans. A control mouse, injected with PBS, is also shown (grey line, open symbols). B) Proportion of the lung weight in respect to body weight, as an indicator of lung inflammation. C) CFUs from the lungs of mice described in A and B. D) Cell size of $C$. neoformans in vitro and in vivo. Cell size (capsule included) was measured in fungal samples obtained from mice infected with high or low C. neoformans doses (see Figure 9A-C). As a control, cell size was measured in cells grown in vitro in Sabouraud or in 10\% Sabouraud buffered at pH 7 with $50 \mathrm{mM}$ MOPS to induce capsule enlargement. The number expresses the proportion of giant cells in each sample, defined as cell with a diameter above $30 \mu \mathrm{m}$. The line in each distribution represents the average of the population. E) Results of the CART analysis. Left panel, prediction of the correlation between inflammation and total fungal cell size. A cell size lower than $35.92 \mu \mathrm{m}$ was strongly associated with increased inflammation. Right panel, corresponding ROC curve, showing a region under the curve of 0.8 . doi:10.1371/journal.ppat.1000945.g009

The proportion of C. neoformans giant cells in infected mouse lung was a function of total microbial burden and pulmonary inflammation. Okagaki et al also found differences in giant/titan cell proportions during infection experiments with MATa and MAT $\alpha$ strains, with the proportion of titan cells being higher when mice were co-infected with both mating types (Okagaki et al, see related article in the current PLoS Pathogens issue). These authors have concluded that titan cell formation is induced by the pheromone signalling pathway. Taking our and their results together, we can conclude that gigantism is a morphological response to host environments that impact cAMP and pheromone signalling pathways, which could regulate the cell cycle with the final purpose of generating giant cells during infection. The fact that the survival of the host is not compromised when the proportion of giant cells is high suggests that giant cells can survive in a local environment in the host for protracted periods of time without disseminating in the setting of intact host immunity, a finding in agreement with Okagaki's report. This notion is consistent with reports that a moderate increase in cell size due to capsule enlargement interferes with $C$. neoformans dissemination from the lung $[52,53]$.

Various studies have suggested that C. neoformans dissemination is associated with intracellular survival inside macrophages [54,55,56,57], but this model cannot be applied to giant cells since they exceed the size of macrophages. Hence, the increased size of the giant cells is likely to be an impediment for their dissemination as they are simply too large to cross biological barriers and/or transverse capillary diameters. Nevertheless, such cells are viable and capable of producing small sized variants when placed in suitable conditions, such as rich agar. Taken together, our findings suggest that giant cell formation could provide the fungus with a strategy for prolonged survival in a host. Cells could conceivably survive through the life of the host and then return to soils when an animal dies. Alternatively, the giant cells could await 


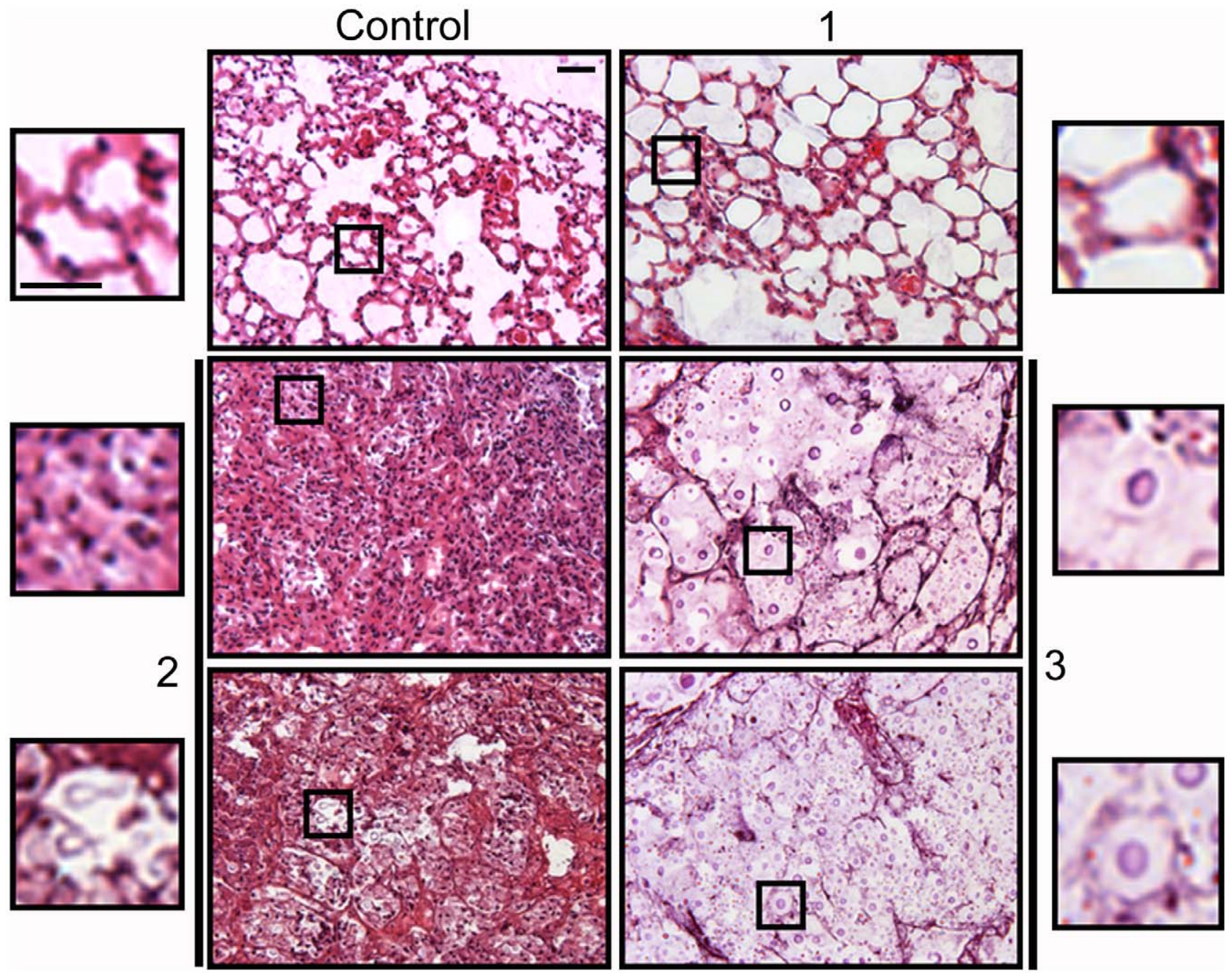

Figure 10. Histological sections of mice infected with different $C$. neoformans inocula. Tissue sections from mice described in Figure 9 were stained with hematoxylin and eosin. Tissue section of control mouse (upper left panel) and three different mice infected with a low $C$. neoformans inocula. Mouse 1, upper right panel; mouse 2, middle and lower left panels; mouse 3, middle and lower right panels (for mice 2 and 3 , two different regions are shown). For each panel, a magnification of a region is shown, which is delimited by an inset. Scale bar in upper left magnification, $25 \mu \mathrm{m}$, and applies to the rest of amplified panels.

doi:10.1371/journal.ppat.1000945.g010

Table 1. Fungal cell size and proportion of giant cells in 16-weeks old mice infected with low and high doses of H99 strain.

\begin{tabular}{|c|c|c|c|c|c|c|c|c|c|c|}
\hline \multirow[b]{3}{*}{ Mouse number } & \multicolumn{10}{|c|}{ Yeast dose (cells/mouse) } \\
\hline & \multicolumn{7}{|l|}{$10^{3}$} & \multicolumn{3}{|l|}{$10^{5}$} \\
\hline & 1 & 2 & 3 & 4 & 5 & 6 & 7 & 1 & 2 & 3 \\
\hline Lung weight (mg) & 240 & 390 & 326 & 340 & 339 & 240 & 309 & 550 & 860 & 413 \\
\hline Mean \pm St. Dev $(\mu \mathrm{m})$ & $34 \pm 6$ & $33 \pm 6$ & $31 \pm 13$ & $20 \pm 5$ & $49 \pm 9$ & $46 \pm 10$ & $44 \pm 11$ & $34 \pm 12$ & $14 \pm 5$ & $40 \pm 10$ \\
\hline Giant cells (\%) & 61 & 74 & 50 & 9 & 91 & 80 & 90 & 67 & 4 & 82 \\
\hline Lower 95\% Cl & 32.3 & 29.5 & 21.4 & 15.5 & 42.1 & 30.4 & 39.4 & 30.1 & 13.3 & 34.1 \\
\hline Upper 95\% Cl & 36.3 & 37.3 & 40.5 & 25 & 57.6 & 62.4 & 49.8 & 37 & 16 & 46.1 \\
\hline
\end{tabular}

Ten CD1 mice (16 weeks old) were infected with $10^{3}$ yeast cells/mouse, and three mice were infected with $10^{5}$ yeast cells/mouse. The animals were killed after a month, and the weight of the lungs was measured. Fungal cells were isolated as described in Materials and Methods, and the mean value, standard deviation, proportion of giant cells (above $30 \mu \mathrm{m}$ ), and the lower and upper $95 \%$ confidence interval were calculated. In three mice of the group infected with a low dose, we did not find any yeast cells, so the data of the other seven mice is represented.

doi:10.1371/journal.ppat.1000945.t001 
permissive host conditions such as in the setting of advanced HIV infection, immunosuppression after organ transplant, or other conditions impairing host immune responses that lead the fungus to proliferate to produce abundant progeny. In this context, it is noteworthy that micro-yeast forms have been described in the lung of infected mice [18,58], suggesting another form of size polymorphism at the other end of the scale. All these findings indicate that during infection, $C$. neoformans can display a wide variation in cell sizes, ranging from micro-forms to giant cells, and suggest that each of these morphotypes have different roles in the pathogenesis of persistence and dissemination.

We are aware of occasional reports of gigantic cells in other fungal species. For example, giant Candida albicans cells with diameter up to $30 \mu \mathrm{m}$ have been described [59,60], and similar large cells have been described for other pathogenic fungi during infection. The arthroconidia of Coccidioides immitis and Coccidioides posadasii swell to form giant spherules (typically $30-150 \mu \mathrm{m}$ in diameter) during mammalian infection and the spherules produce a large number of endospores derived from the cell membrane, each with a single nucleus [35]. When the spherule is mature, the cell membrane is dissolved and the endospores are released. Another example of fungal giant cells occurs in species from the genus Emmonsia, responsible for adiaspiromycosis in humans. Emmonsia crescent cells reach up to $200-700 \mu \mathrm{m}$ during infection and these forms are multinucleate. Emmonsia parva forms cells up to $40 \mu \mathrm{m}$, and they also contain several nuclei [36]. It is possible that gigantism is a general property of unicellular fungi that is expressed under certain conditions. If this is the case, the reproducibility of giant cell formation during cryptococcal infection provides an excellent experimental system for the study of this phenomenon.

In summary, C. neoformans cells can achieve gigantic dimensions during infection and the phenomenon suggests that gigantism may be considered a new form of fungal dimorphism. The occurrence of extraordinarily large cells may enable an adaptation for persistence in certain hosts. The findings for C. neoformans together with the similar reports in other fungi suggest that this may be a general mechanism for fungal survival under certain environments and possibly contribute to persistence during host-pathogen interactions.

\section{Materials and Methods}

\section{Yeast strains and growth media}

For most experiments, serotype A H99 strain was used [61]. In some experiments the following strains were also used: 24067 (serotype D, ATCG); B3501 (serotype D, [62]); RPC3 (cac1::URA5, [37]); RPC7 (cac1::URA5/CAC1, [37]); LCG1 (ras1::ADE2, [38]) and different clinical isolates from the Yeast Collection of the Spanish Mycology Reference Laboratory (CL2132, CL4860, CL5154, CL5632, CL5707, CL5066 and CL4979). Yeasts were grown in Sabouraud liquid medium at $30^{\circ} \mathrm{C}$ with moderate shaking (150 r.p.m.). In some cases, the yeast cells were grown in minimal media $\left(29.4 \mathrm{mM} \mathrm{K \textrm {KH } _ { 2 } \mathrm { PO } _ { 4 } , 1 0 \mathrm { mM } \mathrm { MgSO }}+13 \mathrm{mM}\right.$ Glycine, $3 \mu \mathrm{M}$ thiamine, $15 \mathrm{mM}$ glucose, $\mathrm{pH}$ 5.5). For melanization, L-DOPA containing medium was prepared as in [63]. In other experiments, the cells were transfer from the original Sabouraud culture to $10 \%$ Sabouraud medium pH 7.3 with $50 \mathrm{mM}$ MOPS buffer, as described in [17], to induce capsule enlargement in vitro.

\section{Mouse strains and infection models}

Six to eight weeks old female BALB/c, C57BL/6J (Jackson Laboratories, Bethesda, MD) and CDl mice (Charles River
Laboratories) were used in this study. In some experiments, older CD1 mice (16 weeks old) were also used. C. neoformans strains were grown at $30^{\circ} \mathrm{C}$, washed with sterile PBS, and suspended at specific cell densities. Fifty microliters of the selected yeast cell suspension were injected intratracheally into mice previously anesthetized with a xylazine/ketamine mixture, as described [64].

\section{Histology sections of lung tissues}

Lungs were excised from mice at different infection times and fixed in formalin for $48 \mathrm{~h}$ at room temperature. The tissues were then dehydrated and embedded in paraffin using an STP120 Tissue Processor (Microm International, Walldorf, Germany). Then, $5 \mu \mathrm{m}$ tissue sections were obtained using a Leica RM2245 microtome and placed on glass slides. Hematoxylin/eosin staining of the tissue sections was performed using standard protocols.

\section{Fungal cells isolation from lungs of infected mice}

Mice were euthanized at different times after infection and the lungs were removed. Lung tissue was then homogenized in $10 \mathrm{~mL}$ of PBS with $1 \mathrm{mg} / \mathrm{ml}$ collagenase (Roche, Mannheim, Germany). The cell suspension was incubated for $1 \mathrm{~h}$ at $37^{\circ} \mathrm{C}$ with occasional vortex agitation, and washed several times with sterile distilled water. The cells were suspended in sterile distilled water, and immediately placed in fixative for microscopy, in fresh medium for microscopy observation, or in Sabouraud agar at $30^{\circ} \mathrm{C}$ overnight to observe in vitro budding.

\section{Microscopy techniques}

Cells were viewed with different microscopes. In some experiments, an Olympus AX70 microscope was used and pictures were taken with a digital camera using QCapture Suite V2.46 software for Windows. Alternatively, a Leica DMI3000B connected to a DFC300 digital camera with LAS 3.3.1 software, or a Leica DMI 4000B or a Leica DMRD microscope connected to a Leica DC200 digital camera with IM1000 software were used. To visualize the size of the capsule, the cells were mixed with an India ink suspension. Digital Images were processed with Adobe Photoshop 7.0 software (San Jose, CA). For confocal microscopy, a SP5 confocal microscope (Leica Microsystems) was use.

\section{Macrophage-like cell lines and cell culture techniques}

The macrophage-like cell line RAW264.7 was maintained in DMEM medium supplemented with $10 \%$ heat-inactivated fetal bovine serum, $10 \%$ NTCT, and $1 \%$ of non-essential amino acids at $37^{\circ} \mathrm{C}$ in the presence of a $5 \% \mathrm{CO}_{2}$ atmosphere.

\section{Live-imaging of the interaction between macrophages and fungal cells}

For phagocytosis experiments, $5 \times 10^{4}$ macrophages were placed on 96 -well plates and incubated overnight at $37^{\circ} \mathrm{C}$ in the presence of $5 \% \mathrm{CO}_{2}$, so that a total number of $10^{5}$ macrophages was expected after this incubation given a phagocytic cell replication time of approximately $12 \mathrm{~h}$. Fungal cells were added at a 1:2 (macrophage:yeast cells) ratio in $200 \mu \mathrm{L}$ of medium. Yeast cells of regular size were obtained by growing in Sabouraud medium overnight. To isolate giant cells, fungal cells were isolated from the lungs of infected mice as described above. Giant cells were separated from the rest of the fungal population by passing the sample through $11 \mu \mathrm{m}$ filters. Although we defined giant cells as those larger than $30 \mu \mathrm{m}$ (capsule included), we observed that the capsule did not contribute to retention on the filters, since the size of the cell delimited by the cell wall was the main factor associated with retention or passage. The filters containing the giant cells 
were incubated in PBS with shaking for 20 minutes, and the cells were concentrated by centrifugation. After filtration, we observed that the population was significantly enriched in giant cells, being more than $90 \%$ of the sample. Finally, the cells that transited or were retained by the filter were counted using a haemocytometer.

Once regular and giant cells were obtained and exposed to the macrophages, the 96-wells plate was placed under a Leica DMI 4000B microscope using a $20 \times$ objective with a 5\% $\mathrm{CO}_{2}$ environment and $37^{\circ} \mathrm{C}$. Pictures were taken at different time intervals (see figure legend of the corresponding supporting videos). The videos generated by the Leica software were exported as .avi documents and processed with ImageJ (National Institutes of Health, USA, http://rsb.info.nih.gov/ij/index.html) and VidCrop 2.1.0.0 (GeoVid) softwares. The final videos were generated by merging 5 frames per second.

\section{Melanin detection by immunofluorescence}

Suspensions of cells isolated from mouse lung were air-dried on poly-L-lysine-coated slides (Sigma). The slides coated with the cells were washed in PBS, incubated in blocking buffer (Pierce, Rockford, IL) for $1 \mathrm{~h}$ at $37^{\circ} \mathrm{C}$ followed by incubation with $10 \mu \mathrm{g} / \mathrm{ml}$ of the IgM melanin-binding monoclonal antibody $(\mathrm{mAb}) 6 \mathrm{D} 2$ for $1 \mathrm{~h}$ at $37^{\circ} \mathrm{C}$. MAb 6D2 was generated against melanin derived from C. neoformans [27]. After washing, the slides were incubated with a 1:1000 dilution of tetramethyl rhodamine isothiocyanate (TRITG) -conjugated goat anti-mouse (GAM) IgM (Southern Biotechnologies Associates, Inc; Birmingham, AL) for $1 \mathrm{~h}$ at $37^{\circ} \mathrm{C}$. The slides were washed, mounted using a $50 \%$ glycerol, 50\% PBS, and 0.1 M N-propyl gallate solution, and viewed with an Olympus AX70 microscope equipped with fluorescent filters. Negative controls consisted of cells incubated with $\mathrm{mAb} 5 \mathrm{C} 11$, which binds mycobacterial lipoarabinomannan [65], as the primary $\mathrm{Ab}$ or with TRITC-labeled Ab alone.

\section{Scanning electron microscopy}

Yeast cells were washed in PBS and suspended in fixing solution (2\% p-formaldahyde, $2.5 \%$ glutaraldehyde, $0.1 \mathrm{M}$ sodium cacolydate). Cells were then serially dehydrated with ethanol, coated with gold palladium and visualized using a JEOL (Tokyo, Japan) JAM 6400 microscope.

\section{Transmission electron microscopy}

Cells grown in vitro or isolated from the lungs of infected mice (see above) were fixed with $2.5 \%$ glutaraldehyde in $0.1 \mathrm{M}$ sodium cacodylate buffer. The cells were treated with osmium tetraoxide and serially dehydrated. The samples were embedded in epoxy resin and ultrathin sections were obtained, stained with uranyl acetate and lead citrate, and observed in a CM12-Phillips transmission electron microscope.

\section{DMSO and $\gamma$-radiation treatment}

Yeast cells with enlarged capsule were exposed to varying amounts of $\gamma$-radiation from ${ }^{137} \mathrm{Cs}$ to remove layers of the polysaccharide capsule as described [29,66]. Briefly, giant and in vitro-grown cells were washed three times in PBS to remove shed capsular polysaccharides, suspended in $1 \mathrm{~mL}$ of distilled $\mathrm{H}_{2} \mathrm{O}$, and irradiated using a Shepherd Mark I Irradiator at the dose rate of $1388 \mathrm{rads} / \mathrm{min}$. For all experiments, cells were irradiated for 40 minutes. Irradiated cells were collected by centrifugation. In other experiments, the fungal cells were suspended in DMSO as described in [29]. The presence of capsule after the treatments ( $\gamma$-irradiation or DMSO) was visually observed by suspending the cells in India Ink and regular microscopy.

\section{Complement labelling and detection}

Complement (C3; complement protein 3) deposition on the cryptococcal capsule was performed as in [20]. Briefly, C57BL/6J mice were bled from the retro-orbital cavity and serum was obtained by centrifugation. Approximately $2 \times 10^{7}$ cryptococcal cells were suspended in $700 \mu \mathrm{L}$ freshly-obtained serum, and incubated at $37^{\circ} \mathrm{C}$ for $1 \mathrm{~h}$. Cells were extensively washed and suspended in PBS. C3 was then detected using a fluoresceinisothiocyanate (FITG) conjugated GAM C3 antibody $(4 \mu \mathrm{g} / \mathrm{mL}$, Cappel, ICN, Aurora, OH). Yeast washed and not suspended in serum were used as controls. To delineate the capsular edge, $\mathrm{mAb}$ 18B7 $(10 \mu \mathrm{g} / \mathrm{mL})$ specific for GXM [67] was added, and detected using a TRITG conjugated GAM IgGl antibody $(10 \mu \mathrm{g} / \mathrm{ml}$, Southern Biotechnology Associates, Inc). The cells were observed under fluorescent filters with the Olympus AX70 microscope, QCapture Suite V2.46 software for Windows, and Adobe Photoshop 7.0 for Macintosh.

\section{Imaging of daughter cell emergence from the giant mother cells}

Yeast cells were isolated from infected mice as described above, and placed on Sabouraud agar plates for $18 \mathrm{~h} 30^{\circ} \mathrm{C}$. Initially, we tried recording the budding of giant cells by basic microscopy techniques, such as taking pictures every few minutes or seconds. However, the separation of the bud through the capsule of the giant cell was too fast, so we developed a new approach to record the phenomenon. The surface agar plate was observed with an Olympus AX70 microscope to visualize and continuously record giant cells. To record real-time daughter cell emergence, the cells were observed in the computer screen with the "Preview" option, and the image of the screen was recorded with a Digital Handycam Sony Camcorder affixed to a tripod. The videos were converted into digital files using Windows Movie Maker software provided by Microsoft Windows and processed with the Quick Media Converter (V. 3.6.5) software. Although this method provided lower resolution than the regular CCD used in microscopy, it permitted a precise measurement of the phenomenon.

\section{XTT viability assay}

Giant cells were obtained by filtering the yeasts obtained from the lung of infected mice through $22 \mu \mathrm{m}$ filters. Then, the yeast cells were separated from the filter by gently shaking the filters in $20 \mathrm{~mL}$ of water in $50 \mathrm{~mL}$ centrifuge tubes. After 20 minutes, the filters were removed, and the tubes centrifuged at 2000 r.p.m. Then, the cells were suspended in $2 \mathrm{~mL}$ of sterile water and the cell concentration was estimated using a haemocytometer. Approximately $10^{5}$ giant cells were placed on 96 wells plates. In parallel, regular cells were obtained by overnight incubation in Sabouraud, washed with sterile water and counted with a haemocytometer. Then, the same number of cells $\left(10^{5}\right)$ was placed in 96-wells plates. As negative controls, equal numbers of giant and regular cells were heat-inactivated $\left(45\right.$ minutes at $60^{\circ} \mathrm{C}$ ) and placed in different wells of the 96-wells plates. Viability measurement based on the reduction of 2,3-bis(2-methoxy-4nitro-5-sulfophenyl)-2H-tetrazolium-5-carboxanilide inner salt (XTT) by living cells was performed as described in [21] with minor modifications, which involved the use of $1 \mathrm{mg} / \mathrm{mL}$ of XTT and $25 \mu \mathrm{M}$ menadione. Optical density at $450 \mathrm{~nm}$ was recorded every 30 minutes for 18 hours in a iEMS Spectrophotometer (Thermofisher). Differences in metabolic activities were calculated by fold differences in the optical densities of the different wells. 


\section{Indirect immunofluorescence}

To detect capsular features, we observed the immunofluorescence pattern after incubating the cells with the $\mathrm{mAb} 18 \mathrm{~B} 7$ to the capsular polysaccharide as described above (see complement labelling and detection section), but using goat anti-mouse IgG1FITC conjugated as the detection Ab. Yeast washed and incubated with the IgG1-FITC alone were used as controls. In some experiments, calcofluor $(10 \mu \mathrm{g} / \mathrm{mL})$ was included to visualize the cell wall.

\section{Wheat germ agglutinin staining}

To observe the presence of chitin-like structures, fungal cells with enlarged capsule (incubated in 10\% Sabouradud in $50 \mathrm{mM}$ MOPS buffer pH 7.3) were treated as in [33]. Briefly, the cells were washed with PBS and suspended in 4\% p-formaldehyde cacodylate buffer $(0.1 \mathrm{M}, \mathrm{pH} 7.2)$ and incubated for $30 \mathrm{~min}$ at room temperature. The fixed cells were washed in PBS and suspended in $100 \mu \mathrm{l}$ of a $5 \mu \mathrm{g} / \mathrm{mL}$ of WGA conjugated to Alexa 594 (Molecular Probes, Invitrogen) for 1 hour at $37^{\circ} \mathrm{C}$. Cell suspensions were mounted over glass slides and photographed with a Leica DMI 3000B fluorescence microscope.

\section{Vacuole staining and visualization by confocal microscopy}

To identify the vacuole in the yeast cells, we used the specific dye MDY-64 (Molecular Probes, Invitrogen, Eugene, Oregon) following the manufacturer's recommendations. Briefly, the cells were suspended in $10 \mathrm{mM}$ HEPES buffer $(\mathrm{pH} 7.4)$ supplemented with 5\% glucose. MDY-64 was dissolved in DMSO, and added to $10^{6}$ cells at a final concentration of $10 \mu \mathrm{M}$. The cells were incubated for 5 minutes at room temperature, and washed twice with the same buffer. The cells were observed with a SP5 confocal microscope (Leica Microsystems).

\section{Cellular DNA content}

Cells were isolated as described above and fixed by heating the cells at $60^{\circ} \mathrm{C}$ for 45 minutes in PBS buffer. Then, the cells were separated in two parallel samples, and propidium iodide was added to one of them at a final concentration of $10 \mu \mathrm{g} / \mathrm{mL}$. DNA content was analyzed using a FACSCalibur cytometer (Becton Dickinson). As a control, cells grown in vitro in Sabouraud medium were also analyzed.

\section{Nuclear staining}

To visualize the nucleus, the cells were treated with $3.7 \%$ formaldehyde for 30 minutes. Then, the cells were washed with PBS and DAPI was added at $0.3 \mu \mathrm{g} / \mathrm{mL}$. The cells were incubated for 10 minutes at $37^{\circ} \mathrm{C}$, and then washed twice with PBS. Finally, fluorescence was visualized in a Leica DM3000 microscope.

\section{Real-time PCR}

Giant cells were obtained by filtering the lung extracts through $22 \mu \mathrm{m}$ filters as above. The filters were then placed in $50 \mathrm{~mL}$ tubes containing $20 \mathrm{~mL}$ of sterile water with moderate shaking, and after 20 minutes, the filters were removed. The tubes were centrifuged, and the pellet suspended in $0.5 \mathrm{~mL}$ of sterile water. Then, the cell concentration was determined using a haemocytometer. In parallel, cells obtained from a fresh liquid culture in Sabouraud were counted, and a cell suspension was prepared at the same concentration as that calculated for the giant cells. A real-time PCR using whole cells was then designed using equivalent numbers of the different cell types in the well. The reaction (final volume of $20 \mu \mathrm{L}$ ) contained $2.8 \times 10^{3}$ or $2.8 \times 10^{2}$ cells, $1.5 \mathrm{mM} \mathrm{MgCl}_{2}$, and $0.8 \mu \mathrm{M}$ of ITS1 (5'TCGGTAGGTGAACCTGCGG3') and ITS2 (5'GCTGCGTTCTTCATCGATGC3') oligonucleotides, which amplify the ITS1 region from the ribosomal DNA. The real time was performed using the SensiMix Kit (Quantance) using the enzymes and SYBR green concentrations recommended by the manufacturer. The reaction mix was placed in a 96-wells plate and PCR was performed in a LC480 real-time PCR machine (Roche). We included wells with a known concentration of C. neoformans genomic DNA (20, 2, 0.2 and $0.02 \mathrm{ng}$ ) to quantify the results. The PCR was performed according to the following protocol: initial step of 10 minutes at $95^{\circ} \mathrm{C}$ and 45 amplification cycles $\left(10\right.$ seconds at $95^{\circ} \mathrm{C}, 5$ seconds at $54^{\circ} \mathrm{C}$ and 30 seconds at $72^{\circ} \mathrm{C}$ ). Once the PCR was finished, a standard curve was calculated using the wells of the known genomic DNA concentration, and this curve was used to calculate the estimate of DNA present in each of the samples.

\section{Classification and Regression Trees (CART) analysis}

The CART system was proposed by Breiman et al. [68], and is characterized by binary-split searches, automatic self-validation procedures and surrogate splitters. This analysis is used to find associations between events with statistical support. CART analysis (CART 6.0 Salford Systems, Ca., USA) was used to find associations between giant cell formation and inflammation in the lungs. This analysis was performed with the following methodological conditions, Gini method, minimum cost tree regardless of the size for selecting the best tree, $10 \mathrm{v}$-fold-cross-validation, equal priors, no costs, and no penalties. Relative error of 0 means no error or perfect fit, whereas 1 represents the performance of random guessing. The statistical support for this association is given by the ROC curve. In this graph, specificity (false positive rate) vs. sensitivity (true positives rate) is calculated, and the area under the curve is analysed. When this area is 1 (100\% of sensitivity and $0 \%$ false positives), a total agreement for the prediction is obtained. An area of 0.5 or below is indicative of random guess.

\section{Oxidative stress susceptibility}

Yeast cells (regular and giant) were obtained as described above. The cells were incubated in PBS with or without $1 \mathrm{mM} \mathrm{H}_{2} \mathrm{O}_{2}$ at a cell density of $10^{4}$ cells $/ \mathrm{mL}$. After two hours of incubation at $37^{\circ} \mathrm{C}, 100 \mu \mathrm{L}$ of each sample was plated on Sabouraud agar medium. In addition, a 1/10 dilution was done in PBS, and $100 \mu \mathrm{L}$ of this dilution was also plated. The plates were incubated at $30^{\circ} \mathrm{C}$ for 48 hours and the colonies were enumerated. The survival was expressed as the percentage of colonies counted in the samples incubated with $\mathrm{H}_{2} \mathrm{O}_{2}$ compared to colonies of control samples not exposed to the oxidative agent.

\section{Statistical analysis}

Normal distribution in group samples were assessed using the Shapiro-Wilk and Kolmogorov-Smirnov tests using Unistat 5.0 (Unistat Ltd, London, England) and Analyse-it (Analyse-it Ltd, Leeds, England) softwares for Excel. Statistical differences between groups were tested using Student's t-Test (normal distributions) or KruskalWallis test (non-parametric test for non-normally distributed samples). Differences were considered significant when $p$ value was below 0.05 .

\section{Ethics statement}

All the experiments involving the use of animals have been performed following the guidelines of the Bioethical and Animal Welfare Committee of the Instituto de Salud Carlos III (approved protocol PA-349, to be performed at the National Centre for Microbiology). 


\section{Supporting Information}

Video S1 Live imaging of giant cells budding in vitro. Giant cells were obtained from infected mice as described in Materials and Methods and in Figure 4 legend. Live imaging of budding was recorded and processed as described in Materials and Methods.

Found at: doi:10.1371/journal.ppat.1000945.s001 (2.39 MB AVI)

Video S2 Live imaging of giant cells budding in vitro. Giant cells were obtained from infected mice as described in Materials and Methods and in Figure 4 legend. Live imaging of budding was recorded and processed as described in Materials and Methods. Found at: doi:10.1371/journal.ppat.1000945.s002 (0.18 MB WMV)

Video S3 Live imaging of giant cells budding in vitro. Giant cells were obtained from infected mice as described in Materials and Methods and in Figure 4 legend. Live imaging of budding was recorded and processed as described in Materials and Methods. Found at: doi:10.1371/journal.ppat.1000945.s003 (1.71 MB AVI)

Video S4 Live imaging of giant cells budding in vitro. Giant cells were obtained from infected mice as described in Materials and Methods and in Figure 4 legend. Live imaging of budding was recorded and processed as described in Materials and Methods. Found at: doi:10.1371/journal.ppat.1000945.s004 (2.94 MB AVI)

Video S5 Phagocytosis of C. neoformans by murine-like macrophages. The video shows the interaction of RAW264.7 macrophage cell lines exposed to C. neoformans $\mathrm{H} 99$ strain at a ratio 1:2. Videos were performed as described in Materials and Methods. Pictures were taken every 5 minutes, and 5 frames per second are shown in the video ( 1 second of the video is equivalent to 25 minutes of real time). A field of $100 \mu \mathrm{m}$ width is shown.

Found at: doi:10.1371/journal.ppat.1000945.s005 (5.46 MB AVI)

Video S6 Macrophage fusion after C. neoformans phagocytosis and cell division. RAW264.7 macrophage cell lines were exposed to C. neoformans $\mathrm{H} 99$ strain at a ratio 1:2. Videos were performed as described in Materials and Methods. Pictures were taken every 5 minutes, and 5 frames per second are shown in the video ( 1 second of the video is equivalent to 25 minutes of real time). A field of $100 \mu \mathrm{m}$ width is shown.

Found at: doi:10.1371/journal.ppat.1000945.s006 (6.16 MB AVI)

\section{References}

1. Casadevall A, Pirofski LA (2003) The damage-response framework of microbial pathogenesis. Nat Rev Microbiol 1: 17-24

2. Whiteway M, Bachewich C (2007) Morphogenesis in Candida albicans. Annu Rev Microbiol 61: 529-553.

3. Sudbery P, Gow N, Berman J (2004) The distinct morphogenic states of Candida albicans. Trends Microbiol 12: 317-324.

4. Liu H (2001) Transcriptional control of dimorphism in Candida albicans. Curr Opin Microbiol 4: 728-735.

5. Maresca B, Kobayashi GS (1989) Dimorphism in Histoplasma capsulatum: a model for the study of cell differentiation in pathogenic fungi. Microbiol Rev 53: 186-209.

6. Kane J (1984) Conversion of Blastomyces dermatitidis to the yeast form at 37 degrees C and 26 degrees C. J Clin Microbiol 20: 594-596.

7. Maresca B, Kobayashi GS (2000) Dimorphism in Histoplasma capsulatum and Blastomyces dermatitidis. Contrib Microbiol 5: 201-216.

8. Park BI, Wannemuehler KA, Marston BJ, Govender N, Pappas PG, et al. (2009) Estimation of the current global burden of cryptococcal meningitis among persons living with HIV/AIDS. AIDS 23: 525-530.

9. Casadevall A, Perfect JR (1998) Cryptococcus neoformans; Press A, ed. Washington DC: ASM Press

10. Cherniak R (1988) Soluble polysaccharides of Cryptococcus neoformans. Curr Top Med Mycol 2: 40-54.

11. Goldman DL, Lee SC, Casadevall A (1995) Tissue localization of Cryptococcus neoformans glucuronoxylomannan in the presence and absence of specific antibody. Infect Immun 63: 3448-3453.
Video $\mathbf{S} 7$ C. neoformans intracellular replication. Macrophages and C. neoformans grown in Sabouraud were mixed as described in supplemental Videos S5 and S6. The pictures were taken every 2 minutes, and 5 frames per seconds are shown in the video (1 second of the video is equivalent to 10 minutes of real time).

Found at: doi:10.1371/journal.ppat.1000945.s007 (6.16 MB AVI)

Video S8 Interaction between giant cells and macrophages. Macrophages and C. neoformans giant cells were mixed at 1:2 ratio as described in Materials and Methods. Pictures were taken every 3 minutes, and 5 frames per second are shown in the video (1 second of the video is equivalent to 15 minutes of real time). A field of $100 \mu \mathrm{m}$ width is shown.

Found at: doi:10.1371/journal.ppat.1000945.s008 (5.09 MB AVI)

Video S9 Interaction between giant cells and macrophages. Macrophages and C. neoformans giant cells were mixed at 1:2 ratio as described in Materials and Methods. Pictures and video were taken and assemble as described in Supporting Video S8. Scale bar denotes $50 \mu \mathrm{m}$.

Found at: doi:10.1371/journal.ppat.1000945.s009 (2.04 MB WMV)

\section{Acknowledgments}

We thank Josefa Casas for her technical support, Laureano Cuevas and Esperanza Pérez Pastrana for their help obtaining the TEM images, Fernando Gonzalez from the Confocal Analytical Imaging Facility from the National Centre for Microbiology for his assistance with the confocal microscope, and Susana Sánchez for her help with the real-time PCR protocols. O.Z. warmly thanks his brother Rafael Zaragoza for his help in the final editing of some of the supporting videos shown in this article. J.L Rodríguez-Tudela, M. Cuenca-Estrella and O. Zaragoza belong to the Spanish Network for Research in Infectious Diseases (REIPI, RD/06/ 0008/0010). Finally, we would like to thank Drs. Kirsten Nielsen, Joe Heitman and Françoise Dromer for sharing with us their unpublished results about the formation of C. neoformans "titan cells" during murine infection.

\section{Author Contributions}

Conceived and designed the experiments: OZ MCE JLRT AC. Performed the experiments: OZ RGR JDN. Analyzed the data: OZ JLRT AC. Contributed reagents/materials/analysis tools: AC. Wrote the paper: OZ JDN MCE JLRT AG.

12. Lee SC, Casadevall A, Dickson DW (1996) Immunohistochemical localization of capsular polysaccharide antigen in the central nervous system cells in cryptococcal meningoencephalitis. Am J Pathol 148: 1267-1274.

13. Vecchiarelli A (2007) Fungal capsular polysaccharide and T-cell suppression: the hidden nature of poor immunogenicity. Crit Rev Immunol 27: 547-557.

14. Yauch LE, Lam JS, Levitz SM (2006) Direct inhibition of T-cell responses by the Cryptococcus capsular polysaccharide glucuronoxylomannan. PLoS Pathog 2: e120.

15. Zaragoza O, Rodrigues ML, De Jesus M, Frases S, Dadachova E, et al. (2009) The Capsule of the Fungal Pathogen Cryptococcus neoformans. Adv Appl Microbiol 68: 133-216.

16. McClelland EE, Bernhardt P, Casadevall A (2006) Estimating the relative contributions of virulence factors for pathogenic microbes. Infect Immun 74: 1500-1504

17. Zaragoza O, Casadevall A (2004) Experimental modulation of capsule size in Cryptococcus neoformans. Biol Proced Online 6: 10-15.

18. Feldmesser M, Kress Y, Casadevall A (2001) Dynamic changes in the morphology of Cryptococcus neoformans during murine pulmonary infection. Microbiology 147: 2355-2365.

19. Maxson ME, Cook E, Casadevall A, Zaragoza O (2007) The volume and hydration of the Cryptococcus neoformans polysaccharide capsule. Fungal Genet Biol 44: 180-186.

20. Zaragoza O, Taborda CP, Casadevall A (2003) The efficacy of complementmediated phagocytosis of Cryptococcus neoformans is dependent on the location of C3 in the polysaccharide capsule and involves both direct and indirect C3mediated interactions. Euro J Immnunol 33: 1957-1967. 
21. Zaragoza O, Chrisman CJ, Castelli MV, Frases S, Cuenca-Estrella M, et al. (2008) Capsule enlargement in Cryptococcus neoformans confers resistance to oxidative stress suggesting a mechanism for intracellular survival. Cell Microbiol 10: 2043-2057.

22. Cruickshank JG, Cavill R, Jelbert M (1973) Cryptococcus neoformans of unusual morphology. Appl Microbiol 25: 309-312.

23. D'Souza CA, Alspaugh JA, Yue C, Harashima T, Cox GM, et al. (2001) Cyclic AMP-dependent protein kinase controls virulence of the fungal pathogen Cryptococcus neoformans. Mol Cell Biol 21: 3179-3191.

24. Love GL, Boyd GD, Greer DL (1985) Large Cryptococcus neoformans isolated from brain abscess. J Clin Microbiol 22: 1068-1070.

25. Zaragoza O, Mihu C, Casadevall A, Nosanchuk JD (2005) Effect of amphotericin B on capsule and cell size in Cryptococcus neoformans during murine infection. Antimicrob Agents Chemother 49: 4358-4361.

26. Nosanchuk JD, Valadon P, Feldmesser M, Casadevall A (1999) Melanization of Cryptococcus neoformans in murine infection. Mol Cell Biol 19: 745-750.

27. Rosas AL, Nosanchuk JD, Feldmesser M, Cox GM, McDade HC, et al. (2000) Synthesis of polymerized melanin by Cryptococcus neoformans in infected rodents. Infect Immun 68: 2845-2853.

28. Chaskes S, Frases S, Cammer M, Gerfen G, Casadevall A (2008) Growth and pigment production on D-tryptophan medium by Cryptococcus gattii, Cryptococcus neoformans, and Candida albicans. J Clin Microbiol 46: 255-264.

29. Bryan RA, Zaragoza O, Zhang T, Ortiz G, Casadevall A, et al. (2005) Radiological studies reveal radial differences in the architecture of the polysaccharide capsule of Cryptococcus neoformans. Eukaryot Cell 4: 465-475.

30. Dembitzer HM, Buza I, Reiss F (1972) Biological and electron microscopic changes in gamma radiated Cryptococcus neoformans. Mycopathol Mycol Appl 47: 307-315.

31. Gates MA, Thorkildson P, Kozel TR (2004) Molecular architecture of the Cryptococcus neoformans capsule. Mol Microbiol 52: 13-24.

32. Zaragoza O, Casadevall A (2006) Monoclonal antibodies can affect complement deposition on the capsule of the pathogenic fungus Cryptococcus neoformans by both classical pathway activation and steric hindrance. Cell Microbiol 8: 1862-1876.

33. Rodrigues ML, Alvarez M, Fonseca FL, Casadevall A (2008) Binding of the wheat germ lectin to Cryptococcus neoformans suggests an association of chitinlike structures with yeast budding and capsular glucuronoxylomannan. Eukaryot Cell 7: 602-609.

34. Zaragoza O, Telzak A, Bryan RA, Dadachova E, Casadevall A (2006) The polysaccharide capsule of the pathogenic fungus Cryptococcus neoformans enlarges by distal growth and is rearranged during budding. Mol Microbiol 59: 67-83.

35. Miyaji M, Nishimura K, Ajello L (1985) Scanning electron microscope studies on the parasitic cycle of Coccidioides immitis. Mycopathologia 89: 51-57.

36. de Hoog GS, Guarro J, Gené J, Figueras MJ (2000) Atlas of Clinical Fungi; de Hoog GS, Guarro J, Gené J, Figueras MJ, eds. Utrecht, Reus: Centraalbureau vor Schimmel Cultures, Universitat Rovira i Virgili.

37. Alspaugh JA, Pukkila-Worley R, Harashima T, Cavallo LM, Funnell D, et al. (2002) Adenylyl cyclase functions downstream of the Galpha protein Gpal and controls mating and pathogenicity of Cryptococcus neoformans. Eukaryot Cell 1: 75-84.

38. Alspaugh JA, Cavallo LM, Perfect JR, Heitman J (2000) RAS1 regulates filamentation, mating and growth at high temperature of Cryptococcus neoformans. Mol Microbiol 36: 352-365.

39. Alvarez M, Casadevall A (2006) Phagosome extrusion and host-cell survival after Cryptococcus neoformans phagocytosis by macrophages. Curr Biol 16: 2161-2165.

40. Alvarez M, Casadevall A (2007) Cell-to-cell spread and massive vacuole formation after Cryptococcus neoformans infection of murine macrophages. BMC Immunol 8: 16.

41. Ma H, Croudace JE, Lammas DA, May RC (2007) Direct cell-to-cell spread of a pathogenic yeast. BMC Immunol 8: 15 .

42. Ma H, Croudace JE, Lammas DA, May RC (2006) Expulsion of live pathogenic yeast by macrophages. Curr Biol 16: 2156-2160.

43. Luo Y, Alvarez M, Xia L, Casadevall A (2008) The outcome of phagocytic cell division with infectious cargo depends on single phagosome formation. PLoS One 3: e3219.

44. Cleare W, Casadevall A (1999) Scanning electron microscopy of encapsulated and non-encapsulated Cryptococcus neoformans and the effect of glucose on capsular polysaccharide release. Med Mycol 37: 235-243.
45. Aldea M, Gari E, Colomina N (2007) Control of cell cycle and cell growth by molecular chaperones. Cell Cycle 6: 2599-2603.

46. Sugimoto-Shirasu K, Roberts K (2003) "Big it up": endoreduplication and cellsize control in plants. Curr Opin Plant Biol 6: 544-553.

47. Grebien F, Dolznig H, Beug H, Mullner EW (2005) Cell size control: new evidence for a general mechanism. Cell Cycle 4: 418-421.

48. Cavalier-Smith T (1978) Nuclear volume control by nucleoskeletal DNA, selection for cell volume and cell growth rate, and the solution of the DNA Cvalue paradox. J Cell Sci 34: 247-278.

49. Kondorosi E, Roudier F, Gendreau E (2000) Plant cell-size control: growing by ploidy? Curr Opin Plant Biol 3: 488-492.

50. Mendell JE, Clements KD, Choat JH, Angert ER (2008) Extreme polyploidy in a large bacterium. Proc Natl Acad Sci U S A 105: 6730-6734.

51. Mergaert P, Uchiumi T, Alunni B, Evanno G, Cheron A, et al. (2006) Eukaryotic control on bacterial cell cycle and differentiation in the Rhizobiumlegume symbiosis. Proc Natl Acad Sci U S A 103: 5230-5235.

52. Shea JM, Kechichian TB, Luberto C, Del Poeta M (2006) The cryptococcal enzyme inositol phosphosphingolipid-phospholipase $\mathrm{C}$ confers resistance to the antifungal effects of macrophages and promotes fungal dissemination to the central nervous system. Infect Immun 74: 5977-5988.

53. Moyrand F, Fontaine T, Janbon G (2007) Systematic capsule gene disruption reveals the central role of galactose metabolism on Cryptococcus neoformans virulence. Mol Microbiol 64: 771-781.

54. Charlier C, Nielsen K, Daou S, Brigitte M, Chretien F, et al. (2009) Evidence For A Role Of Monocytes In Dissemination And Brain Invasion By Cryptococcus Neoformans. Infect Immun 77: 120-127.

55. Kechichian TB, Shea J, Del Poeta M (2007) Depletion of alveolar macrophages decreases the dissemination of a glucosylceramide-deficient mutant of Cryptococcus neoformans in immunodeficient mice. Infect Immun 75: 4792-4798.

56. Shao X, Mednick A, Alvarez M, van Rooijen N, Casadevall A, et al. (2005) An innate immune system cell is a major determinant of species-related susceptibility differences to fungal pneumonia. J Immunol 175: 3244-3251.

57. Zaragoza O, Alvarez M, Telzak A, Rivera J, Casadevall A (2007) The relative susceptibility of mouse strains to pulmonary Cryptococcus neoformans infection is associated with pleiotropic differences in the immune response. Infect Immun 75: 2729-2739.

58. Nosanchuk JD, Rosas AL, Lee SC, Casadevall A (2000) Melanisation of Cryptococcus neoformans in human brain tissue. Lancet 355: 2049-2050.

59. Bottone EJ, Horga M, Abrams J (1999) "Giant" blastoconidia of Candida albicans: morphologic presentation and concepts regarding their production. Diagn Microbiol Infect Dis 34: 27-32

60. Alasio TM, Lento PA, Bottone EJ (2003) Giant blastoconidia of Candida albicans. A case report and review of the literature. Arch Pathol Lab Med 127: 868-871.

61. Perfect JR, Lang SDR, Durack DT (1980) Chronic cryptococcal meningitis: a new experimental model in rabbits. Am J Pathol 101: 177-194.

62. Kwon-Chung KJ (1976) Morphogenesis of Filobasidiella neoformans, the sexual state of Cryptococcus neoformans. Mycologia 68: 821-833.

63. Garcia-Rivera J, Eisenman HC, Nosanchuk JD, Aisen P, Zaragoza O, et al. (2005) Comparative analysis of Cryptococcus neoformans acid-resistant particles generated from pigmented cells grown in different laccase substrates. Fungal Genet Biol 42: 989-998.

64. Feldmesser M, Kress Y, Novikoff P, Casadevall A (2000) Cryptococcus neoformans is a facultative intracellular pathogen in murine pulmonary infection. Infect Immun 68: 4225-4237.

65. Glatman-Freedman A, Martin JM, Riska PF, Bloom BR, Casadevall A (1996) Monoclonal antibodies to surface antigens of Mycobacterium tuberculosis and their use in a modified enzyme-linked immunosorbent spot assay for detection of mycobacteria. J Clin Microbiol 34: 2795-2802.

66. Maxson ME, Dadachova E, Casadevall A, Zaragoza O (2007) Radial mass density, charge, and epitope distribution in the Cryptococcus neoformans capsule. Eukaryot Cell 6: 95-109.

67. Casadevall A, Cleare W, Feldmesser M, Glatman-Freedman A, Goldman DL, et al. (1998) Characterization of a murine monoclonal antibody to Cryptococcus neoformans polysaccharide that is a candidate for human therapeutic studies. Antimicrob Agents Chemother 42: 1437-1446.

68. Breiman L, Friedman JH, Olshen JH, Stone CG (1984) Classification and regression trees. Belmont: Wadsworth International. 